\title{
Halim El-Dabh's Derabucca Notation and its Implication on Performance Practice
}

\author{
Ryan Joseph Frost
}

Follow this and additional works at: https://researchrepository.wvu.edu/etd

\section{Recommended Citation}

Frost, Ryan Joseph, "Halim El-Dabh's Derabucca Notation and its Implication on Performance Practice" (2015). Graduate Theses, Dissertations, and Problem Reports. 5628.

https://researchrepository.wvu.edu/etd/5628

This Dissertation is protected by copyright and/or related rights. It has been brought to you by the The Research Repository @ WVU with permission from the rights-holder(s). You are free to use this Dissertation in any way that is permitted by the copyright and related rights legislation that applies to your use. For other uses you must obtain permission from the rights-holder(s) directly, unless additional rights are indicated by a Creative Commons license in the record and/ or on the work itself. This Dissertation has been accepted for inclusion in WVU Graduate Theses, Dissertations, and Problem Reports collection by an authorized administrator of The Research Repository @ WVU.

For more information, please contact researchrepository@mail.wvu.edu. 
Halim El-Dabh's Derabucca Notation and its Implication on Performance Practice

$$
\begin{gathered}
\text { by } \\
\text { Ryan Joseph Frost }
\end{gathered}
$$

Research Project submitted to the College of Creative Arts at West Virginia University

in partial fulfillment of the requirements for the degree of

\author{
Doctor of Musical Arts \\ in \\ Percussion Performance
}

D.M.A. Committee

Professor George Willis, M.M., Chair

Dr. Michael Vercelli, D.M.A., Research Advisor

Dr. Mary Ferer, Ph.D.

Professor Alison Helm, M.F.A.

Professor Paul Scea, M.M.

Dr. David Taddie, Ph.D.

School of Music

Morgantown, West Virginia

2015

Keywords: Derabucca, Halim El-Dabh, Notation Copyright 2015 Ryan Joseph Frost 


\author{
ABSTRACT \\ Halim El-Dabh’s Derabucca Notation and its Implication on Performance Practice \\ Ryan Joseph Frost
}

The purpose of this document is to aid a performer's interpretation and preparation of Halim ElDabh's Sonic No. 7 and No. 10, The Miraculous Tale, and Sweet and Prickly Pear. This project highlights the composer's unique method of notating techniques for the derabucca as well as his innovative compositional style in the aforementioned works. The original notational systems employed in these works represent one of the few written attempts to communicate advanced derabucca performance techniques to a classically-trained percussionist in published repertoire. Both prescriptive and descriptive in nature, these notational systems are the most ornate and visual of El-Dabh's writing for derabucca. Performance techniques, exercises, interpretation, and information based on composer interviews are included. It is the author's hope that this study will serve as a guide to interpreting and performing these works, as well as adapting the playing techniques to other instruments. It is the author's additional hope to bring attention to the creative notation systems used, which may be models for other non-western instruments. 


\section{ACKNOWLEDGMENTS}

This document could not have been completed without the assistance of many people. First and foremost, a special thanks to my wife Robin, for being with me every step of the way throughout the entire degree process. Her unwavering love and support has been truly amazing.

I would especially like to thank my research advisor Dr. Michael Vercelli for his endless guidance and for showing me time and again what it is to truly be a mentor. Without his expertise and advice this document would not have been possible.

I would like to thank my graduate committee members Professor George Willis, Dr. Mary Ferer, Professor Alison Helm, Professor Paul Scea, and Dr. David Taddie for their valuable input and support of this research.

Thank you to all of my percussion teachers who have influenced and guided me along the way, especially David Pruett for sparking my interest in the derabucca.

I would like to thank my family for instilling in me an appreciation of music from an early age. Their constant encouragement has been a key to my success.

Most importantly, I would like to thank Halim El-Dabh for agreeing to participate in this project. His willingness to discuss his compositions and experiences were inspiring and gave life to this document. The energy and enthusiasm he has for music is remarkable. Also, a special thanks to Deborah El-Dabh for helping to facilitate the interview process. I appreciate the patience and support they showed me from start to finish. 


\section{TABLE OF CONTENTS}

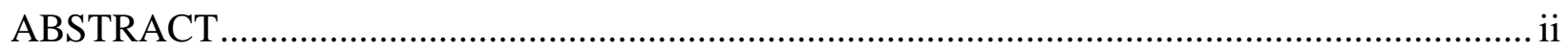

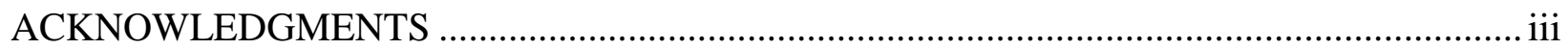

TABLE OF CONTENTS ........................................................................................... iv

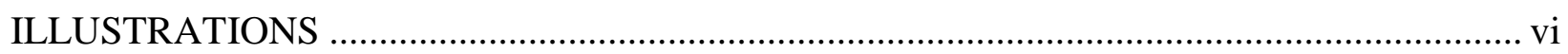

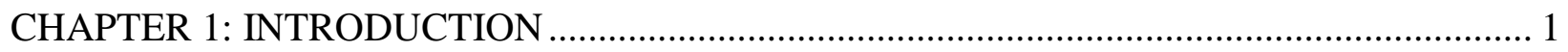

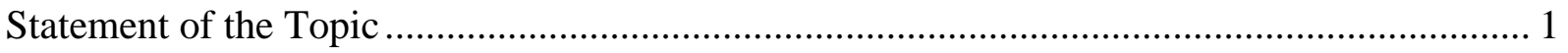

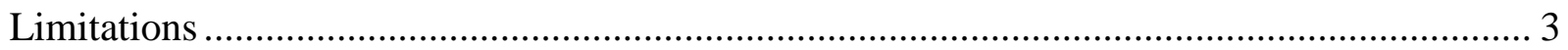

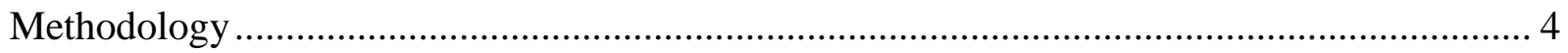

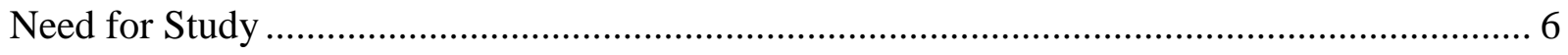

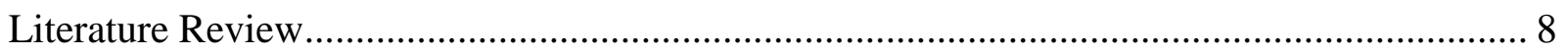

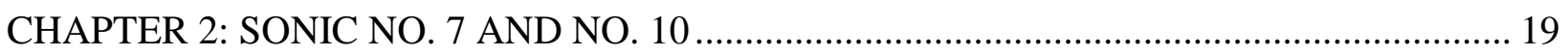

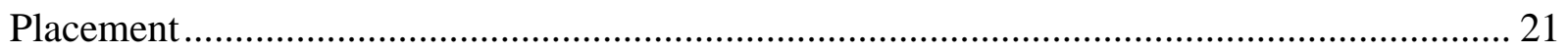

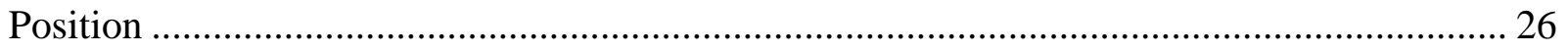

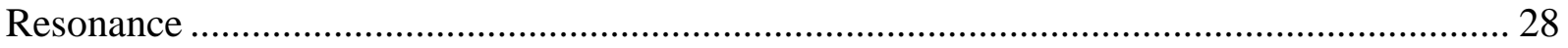

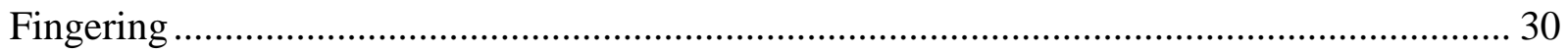

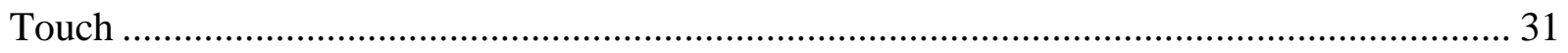

Performance Suggestion and Interpretation .............................................................. 35

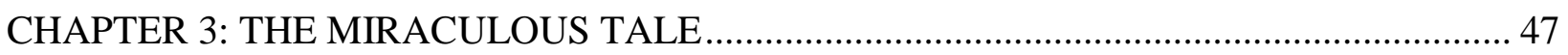

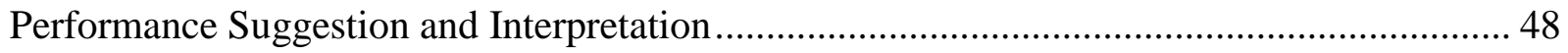

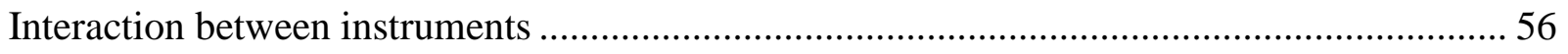

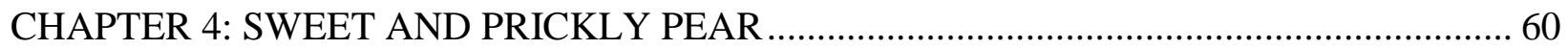

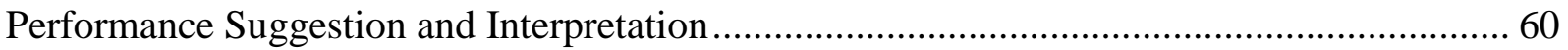

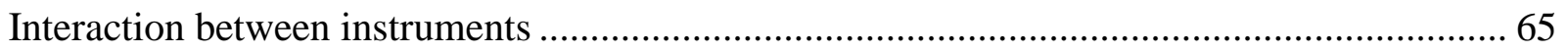


CHAPTER 5: FURTHER APPLICATION OF TECHNIQUES..

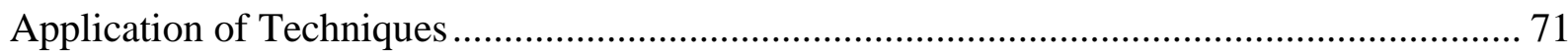

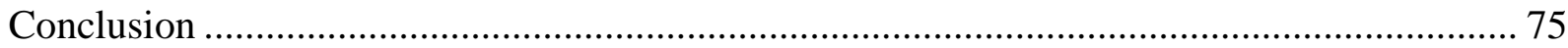

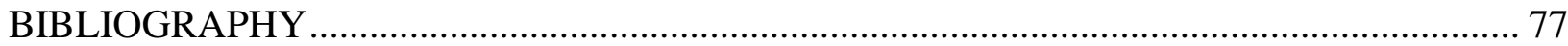




\section{ILLUSTRATIONS}

Figure 1.1. Danziger Notation Example 1 ………………............................................... 13

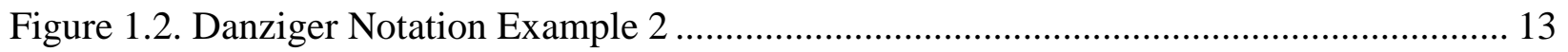

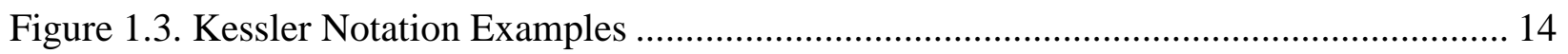

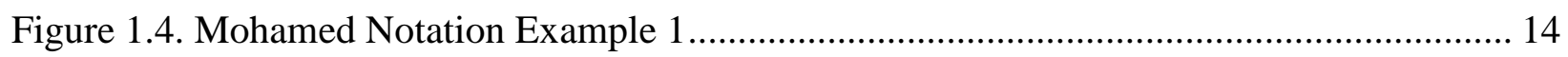

Figure 1.5. Mohamed Notation Example 2 .......................................................................... 15

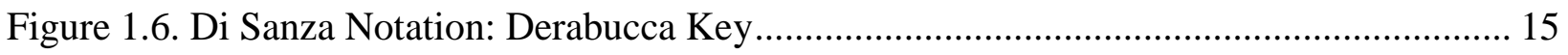

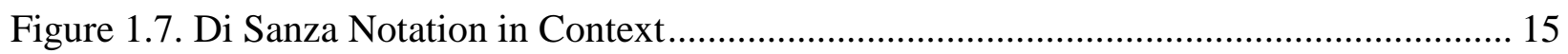

Figure 1.8. El-Dabh's Notation in Context: Sonic No. 7 ........................................................ 17

Figure 1.9. El-Dabh's Notation in Context: The Miraculous Tale …………………...................... 18

Figure 1.10. El-Dabh's Notation in Context: Sweet and Prickly Pear.......................................... 18

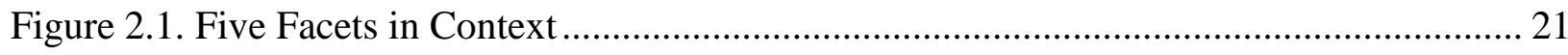

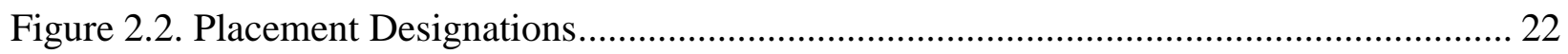

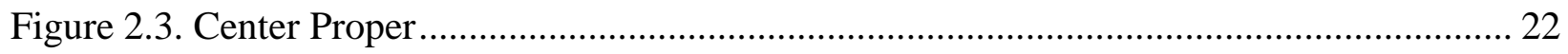

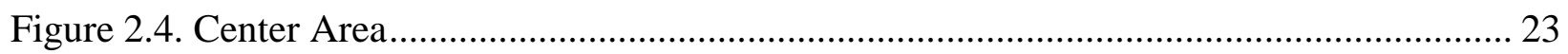

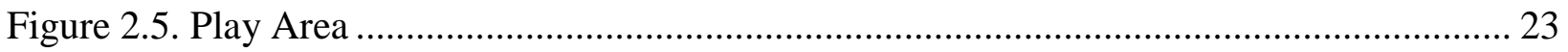

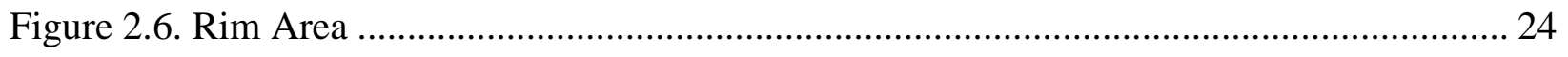

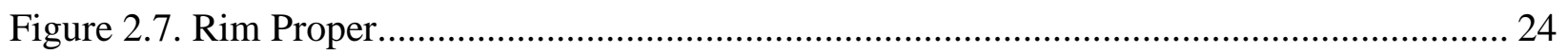

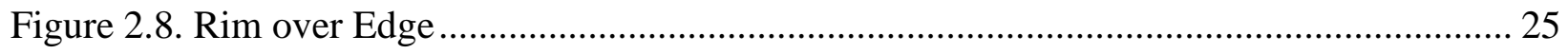

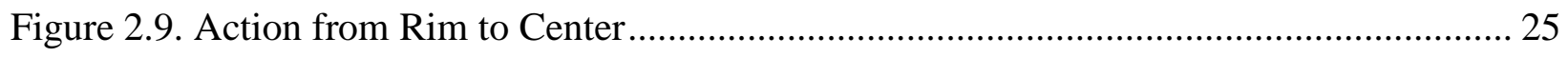

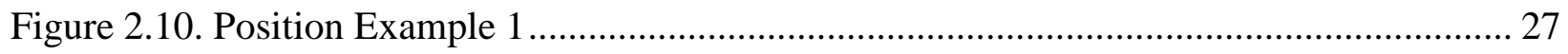

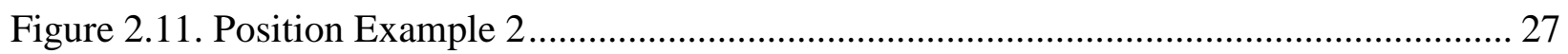

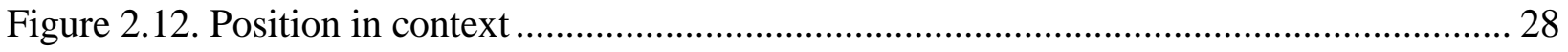

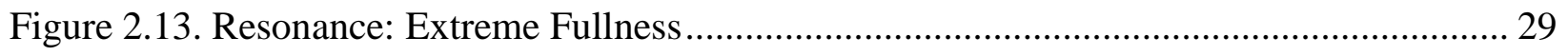




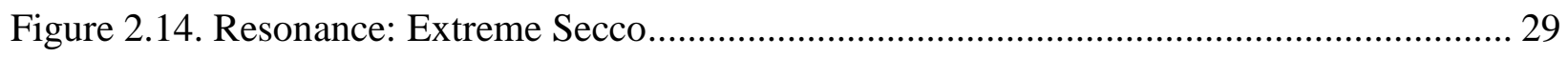

Figure 2.15. Combination of Two Degrees of Resonance ............................................................ 29

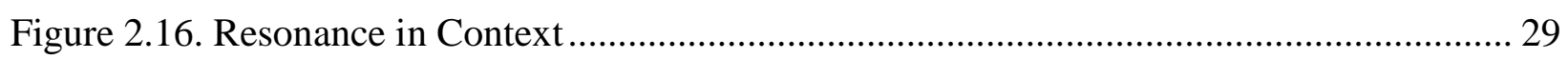

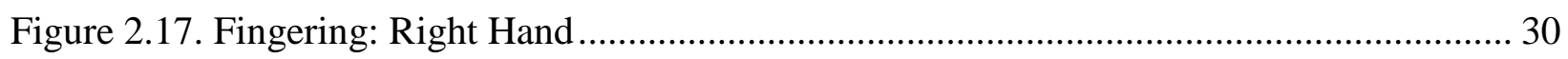

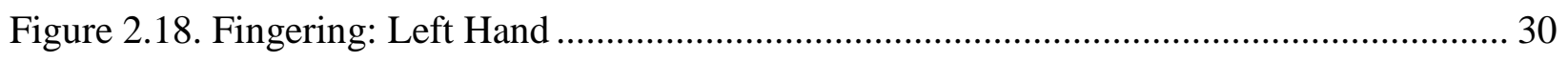

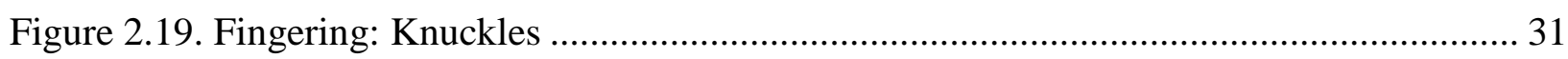

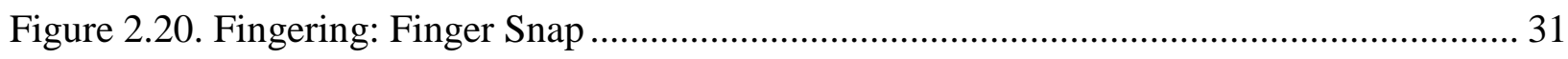

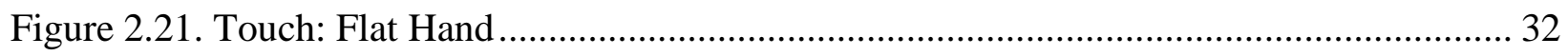

Figure 2.22. Touch: Hand Completely Bent ........................................................................... 32

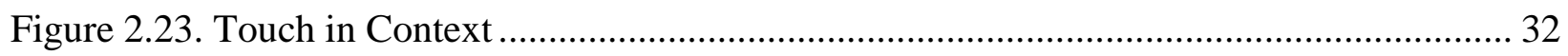

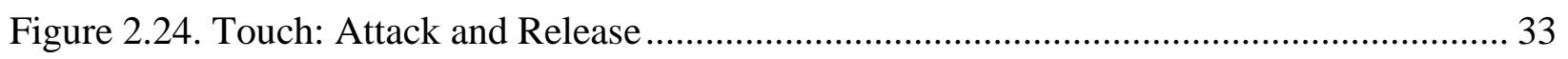

Figure 2.25. Touch: Touch and Retain Hand on Drum .......................................................... 33

Figure 2.26. Touch: Attack and Retain Hand on Drum............................................................ 33

Figure 2.27. Touch: Scratch Surface of Drumhead ................................................................. 34

Figure 2.28. Touch: Pressure on First Note and Release on the Second Note ………………...... 34

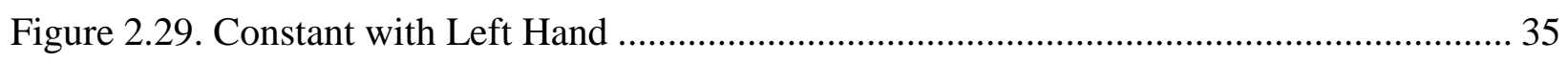

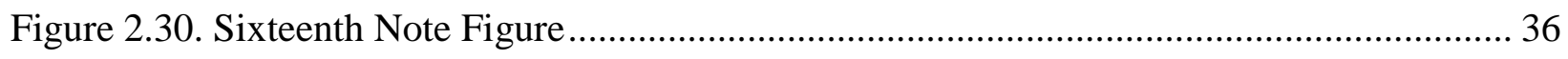

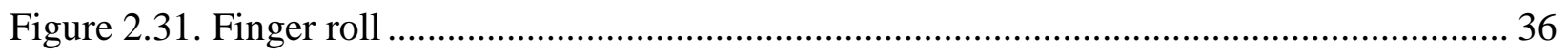

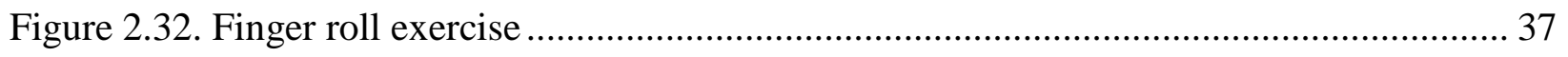

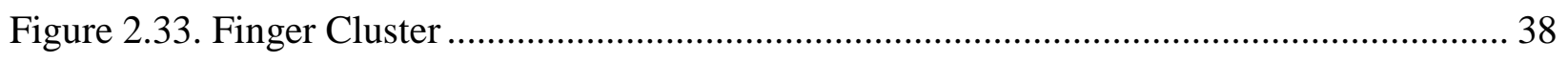

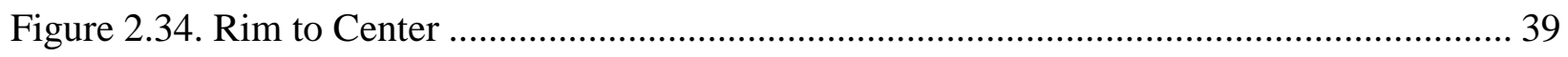

Figure 2.35. Finger Rolls and Placement Change..................................................................... 39

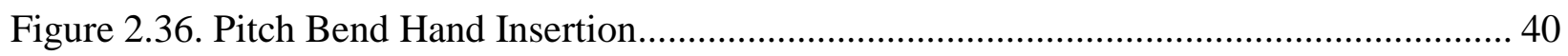

Figure 2.37. Pitch Bend Hand on Drumhead ........................................................................... 41 


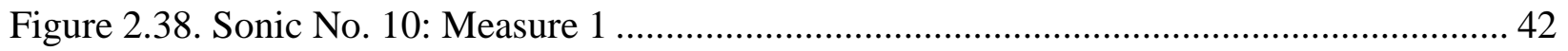

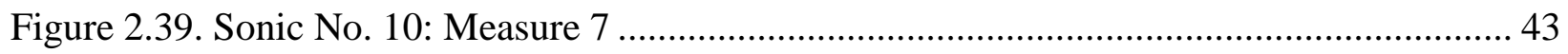

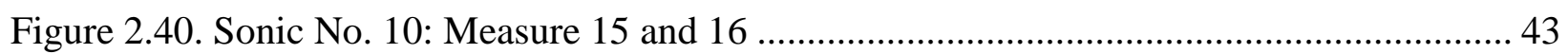

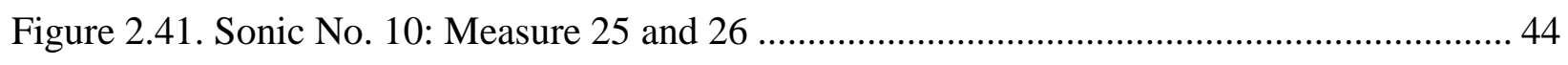

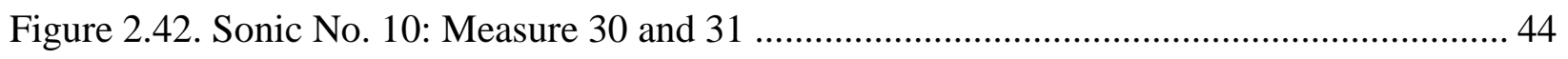

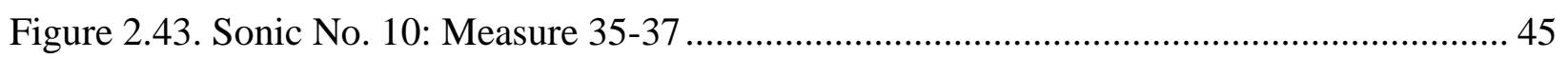

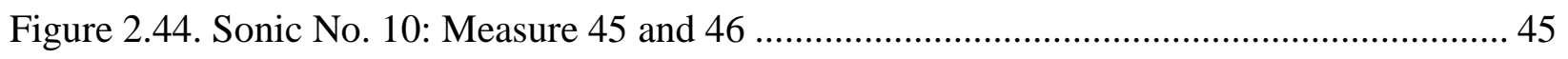

Figure 3.1. Miraculous Tale Notation in Context ...................................................................... 49

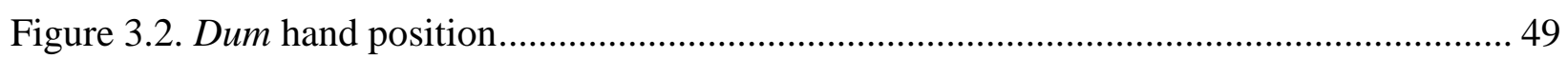

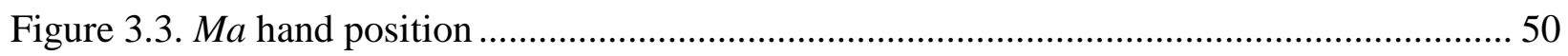

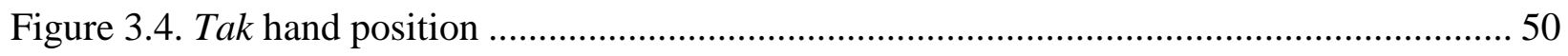

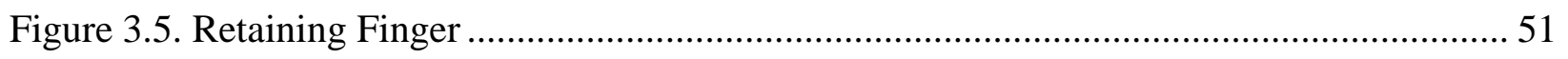

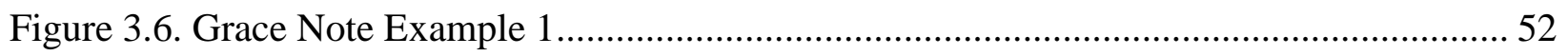

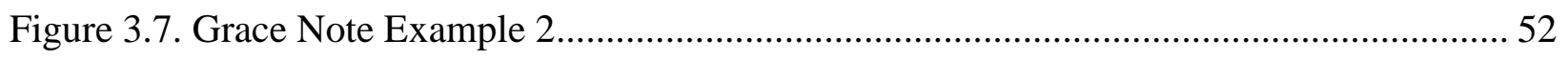

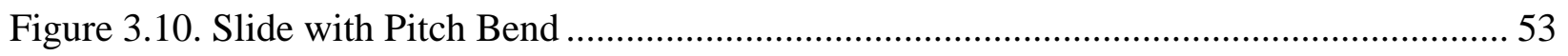

Figure 3.11. Pitch Bend with Hand Insertion ............................................................................ 54

Figure 3.12. One-Handed Roll with Pitch Bend Example 1 ………………............................... 55

Figure 3.13. One-Handed Roll with Pitch Bend Example 2 ……................................................. 55

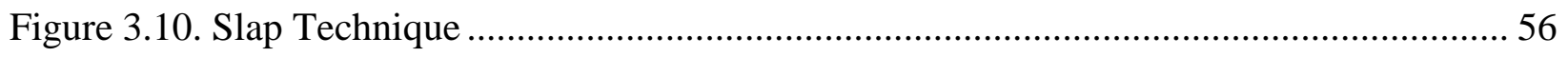

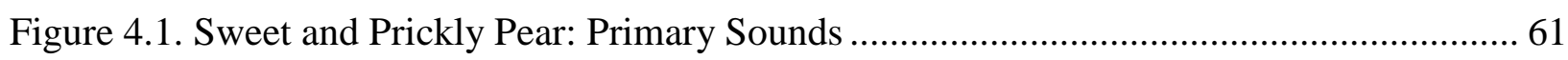

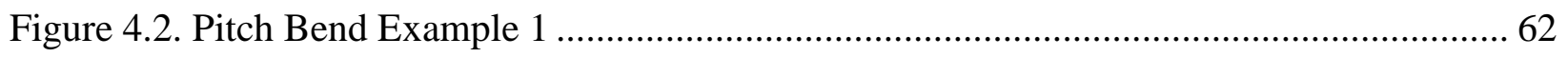

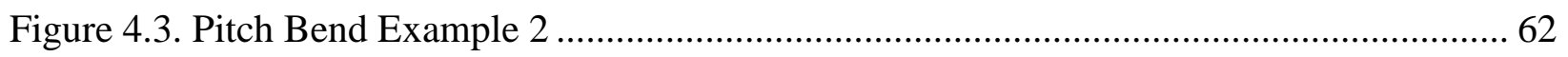

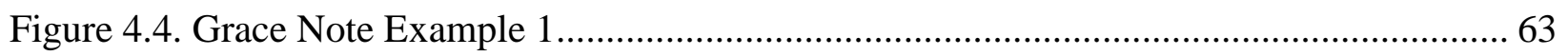

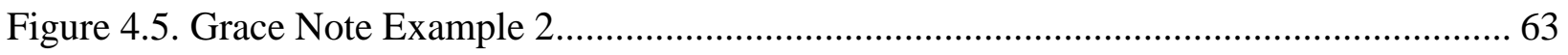




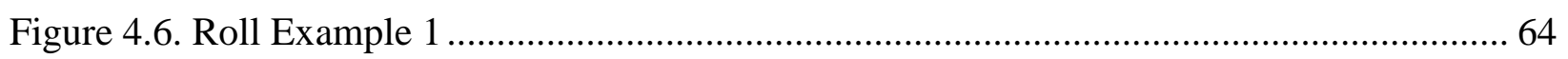

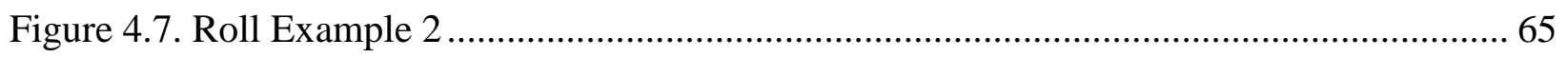

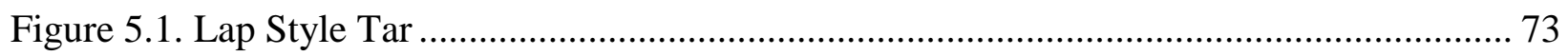




\section{CHAPTER 1: INTRODUCTION}

\section{Statement of the Topic}

Oral tradition associated with the derabucca, ${ }^{1}$ including performance techniques, repertoire, and history, has only recently been documented. Through growing interest of this instrument in the western percussion community, notational challenges of writing for the derabucca have become evident. This study investigates advanced notational techniques as they are found in Egyptian-born, American composer Halim El-Dabh's repertoire and the implication these developments have on performance practice. Selected works for the study include ElDabh's Sonic No. 7 and No. 10, The Miraculous Tale: for Alto Sax and Derabucca, and Sweet and Prickly Pear: for Violin and Derabucca as a platform for this research.

As the derabucca is historically taught through oral tradition, El-Dabh's repertoire provides one of the few notated accounts of complex musical techniques for the instrument. ElDabh created unique notational systems for the derabucca in his compositions to communicate the advanced playing techniques of the instrument to the classically-trained percussionist. This unique musical expression, repertoire, and notational systems are worthy of academic study and further investigation as El-Dabh has documented virtuosic techniques in written form. El-Dabh's repertoire helps the performer build a vocabulary of sound and technique which will enhance a performer's musical voice on the derabucca as well as on other percussion instruments. The unique notational systems El-Dabh created can be utilized as a blueprint by future composers to further develop notational systems for a variety of percussion instruments.

${ }^{1}$ Commonly accepted names for the goblet-shaped drum include, but are not limited to, doumbek, tombak, Arabic tabla, darabuka, derbecki, doumbec, dumbeg and derabucca. For purposes of this project the name derabucca will be used unless referred to in a resource by another name. 
In general, a composer's notation provides varying degrees of specific instructions for the performer to interpret. Musical elements may include articulation markings, dynamics, duration, tempo, and specific instruction for the performer. Other notational forms of communicating musical expression may include graphs, symbols, or other means of describing the desired effect. Each method allows the performer varying degrees of flexibility in interpreting the music. In his article, Prescriptive and Descriptive Music-Writing, Charles Seeger discusses the nature and inherent limitations of musical notation. ${ }^{2}$ As El-Dabh uses varying degrees of detail in his writing for the derabucca, this project will discuss his evolution from specific instruction, or prescriptive, to a more descriptive notational approach. El-Dabh's Sonic No. 7 and No. 10 is prescriptive in that he instructs the performer how and where to strike the derabucca while his descriptive approach used in The Miraculous Tale and Sweet and Prickly Pear describes the sound to be achieved while leaving the performer flexibility in execution.

Results of this investigation include a performance perspective for interpreting El-Dabh's notation and an explanation of the process of achieving the advanced techniques, assisting future performers to successfully interpret El-Dabh's writing for the derabucca. Through performance, interviews, and score analysis, I provide a synthesis and practical explanation for performing the aforementioned works by El-Dabh. This detailed study also includes a chapter that discusses the application of these techniques and musical ideas to other instruments such as the Nubian tar, Moroccan bendir, Arab riqq, Irish bodhran and Nigerian udu drum. The chapter also expands upon how these advanced techniques can assist a performer's ability to improvise and enhance their creativity in soloing.

\footnotetext{
${ }^{2}$ Charles Seeger, "Prescriptive and Descriptive Music-Writing," The Musical Quarterly 44 no. 2 (1958): 186.
} 


\section{Limitations}

This study focuses on three of Halim El-Dabh's published works for the derabucca: Sonic No. 7 and No. 10, The Miraculous Tale, and Sweet and Prickly Pear. These works were selected due to the high level of complexity and detail present in regards to technique, notational development, musical interpretation, and their availability as published literature for the derabucca. Works omitted from this study are either not published or use the derabucca in a basic and supportive role as in El-Dabh's Belly Dance Classic, Mark Ford's The Surface of Life, and Kevin Tuck's Mystical Traveller.

The three selected works are examined individually and then compared with one another according to notation, thematic material, playing techniques, and musical interpretation. This study also examines El-Dabh's notational style for the derabucca and the implication on performance practice. Each work is constructed using a unique and varied notational system demonstrating how El-Dabh's notational style has evolved from providing specific instruction to a more descriptive notational approach.

This project is not intended as a review of the history of musical notations specifically designed for percussion, but is focused on the derabucca writing of Halim El-Dabh in the works listed above. While few other composers have published derabucca works, none of them approach the complexity of El-Dabh's notation. Additionally, because the repertoire of the derabucca is based in oral tradition there is an abundance of unwritten resources for the instrument in media such as CDs, DVDs, and online videos and audio clips. These resources are beyond the scope of this study. 


\section{Methodology}

I began studying the derabucca in 2005 and was fascinated by the expressive qualities of the instrument. Since then, I have enjoyed researching techniques and exploring the sonic capabilities of the instrument by performing in a variety of settings. Incorporating these techniques into my performance has improved my level of artistic expression not only on the derabucca but on other percussion instruments as well. Through the process of seeking resources and music for the instrument, it became clear there was a lack of documentation of history and written repertoire for the derabucca. The process of researching repertoire for the instrument led me to discover Halim El-Dabh's body of literature. The high level of detail found in El-Dabh's notational systems caught my attention and interest. Outside of the brief performance notes indicated in his scores, little has been written about El-Dabh's notational systems and writing for the derabucca, therefore a performer is left to independently interpret unfamiliar notation.

The research for this project provides insight concerning the process of interpreting, realizing, and executing derabucca techniques present in El-Dabh's Sonic No. 7 and No. 10, The Miraculous Tale and Sweet and Prickly Pear. The document is supported by personal interviews with Halim El-Dabh. An in-depth comparative analysis of the works guided the interviews and discussion of El-Dabh's notational evolution. These interviews were recorded on a Zoom H4 Handy Recorder audio device, a Sony HDD Handycam DCR-SR47 video recorder, and TapeACall Pro application for iPhone, version 3.2.2 by Epic Enterprises.

An initial interview was conducted with Professor Halim El-Dabh on Saturday, February 9, 2013 at his home in Kent, Ohio. In reality, the encounter proved to be much more than just an interview. El-Dabh reaffirmed the strong oral tradition associated with the instrument by sharing 
stories, history, a lesson, and by discussing experiences that shaped his writing and musical style for the derabucca. During my lesson with El-Dabh, he continued to offer insight concerning major influences in his writing for the derabucca, techniques used, and his method of notating his musical voice for the instrument. El-Dabh also provided critique, instruction, and demonstration concerning his intention and techniques for the instrument as they pertained to each of the three works. The stories and discussion of his experiences continued over a delicious lunch as we shared Bamya (meat and okra stew), one of El-Dabh's favorite Egyptian dishes. Being able to spend time with El-Dabh throughout the course of the day allowed me to gain insight into his persona from a variety of angles (educator, musician, and composer). At the conclusion of our time together, El-Dabh expressed his openness to continued collaboration on this project and agreed to be available throughout the course of this study. Follow up interviews were conducted via phone and email on December 7 and 10, 2013; March 1 and May 11, 2014; February 12, 2015; and April 4, 2015.

Conclusions are based upon my preparation and performance of the selected works and enhanced by a synthesis of in-depth score study concerning notation, thematic material, playing techniques, and musical interpretation, coupled with the information gathered through the interview process. The findings of this study are organized into a performance guide for future performers of El-Dabh's works and include a chapter discussing further application of these techniques. As these techniques are useful in a variety of musical situations, the mastery of this repertoire will develop a performer's sound, artistic expression, and enhance musical vocabulary, style, and nuance on a variety of instruments. 


\section{Need for Study}

With increased access and study of music of non-Western cultures, there is a rising expectation for percussionists to be proficient and knowledgeable about world instruments. Examples of prominent recent works scored for non-Western percussion instruments include Four Solos for Frame Drums and Recital Suite for Djembe by B. Michael Williams, Handful by N. Scott Robinson, Darabukka Suite by Siegfried Fink, Hands On'Semble Songbook by John Bergamo, Randy Gloss, Andrew Grueschow, and Austin Wrinkle and Concerto for Darabukka and Percussion Quartet by Anthony Di Sanza. As the derabucca continues to gain recognition, it will be important for percussionists to be prepared to interpret, realize, and execute various techniques on the derabucca. The ability to interpret notation for this instrument as well as familiarity with techniques for the instrument is essential to successful derabucca performance. Composer Halim El-Dabh, an advocate of writing for the derabucca, has greatly expanded the detail and level of notation for the instrument.

As a composer of significant recognition, El-Dabh has established his prominence with over 300 works to his credit. After discovering a talent for music at an early age, El-Dabh departed from Egypt to study music composition in the United States. During his career, he has composed for instruments such as piano, flute, saxophone, guitar, string orchestra, voice, percussion ensemble, timpani and frequently uses the derabucca in his solo and chamber works. He has been awarded two Rockefeller Foundation fellowships, two Fulbright Awards, two Guggenheim Fellowships, three residencies at the McDowell Colony, and grants from Meet the 
Composer, Ohio Arts Council, The American Philosophical Society, and Kent State University in recognition of his musical contributions. ${ }^{3}$

Despite his distinction as a contemporary composer, there are no current publications that offer insight into Halim El-Dabh's writing for the derabucca. Academic research is warranted due to El-Dabh's unique contribution of specialized notation, techniques, and repertoire for the instrument. The information gathered during this project will help future percussionists understand and perform the notational and technical demands of Halim El-Dabh's writing for derabucca. Outside of El-Dabh's repertoire there are no published works that detail and present extensive notated techniques for the derabucca. There is a gap between the basics presented in the available instructional material and the virtuosic playing that is associated with the instrument. El-Dabh's compositions are a tangible connection between fundamental instructional material and non-notated advanced performance techniques found in virtuosic performances.

The diversity of sonic qualities found in El-Dabh's works gives the performer insight into musical qualities of the instrument that otherwise has not been documented in written form. Advanced techniques are a traditional part of derabucca performance that have typically been disseminated through oral tradition and have more recently been documented in musical recordings such as the CD Ozlem by the group Turku ${ }^{4}$ and online video clips such as Yousif Sheronick's solo demonstrating the diverse sounds of the instrument. ${ }^{5}$ El-Dabh's attention to detail will enhance the technical ability of the performer and assist in creating an individual expressive voice on the instrument. As an oral tradition, there is little documentation about

\footnotetext{
${ }^{3}$ Halim El-Dabh, Sweet and Prickly Pear (Kent, OH: Halim El-Dabh Music, LLC, 2010), liner notes.

${ }^{4}$ Turku, Ozlem, CD.

5 Yousif Sheronick “Juilliard Darbuka Solo” (video), September 16, 2009, accessed December 14, 2012 , http://www.youtube.com/watch?v=zENRNvFs-rk.
} 
derabucca performance practice. El-Dabh's repertoire serves as a model for the classicallytrained percussionist to study techniques and subtleties of the instrument. Not only will performers gain from this insight, but composers may also benefit from El-Dabh's detailed notation in that it provides a method of conceptualizing these advanced musical sounds and expressive aspects of the instrument. It is important to document El-Dabh's contributions as they represent an important new direction in the instrument's development.

Although his musical works will be useful for study beyond his lifetime, there is a great amount of interpretive information that can only be gained through personal interaction between the composer and researcher. My interviews with El-Dabh allowed for a greater understanding of the intention, personal connection, and inspiration behind these three works. This type of interaction offers the opportunity for a more informed and accurate interpretation of El-Dabh's repertoire.

\section{Literature Review}

While there is a limited number of resources available pertaining to the derabucca, the literature on which this study is based is divided into the following categories. These groups were created from the information available in the resources.

1. Derabucca history

2. Performance and technique

3. Notation and repertoire

\section{Derabucca history}

In the DVD The Art of Arabic Drumming, derabucca artist Trevor Salloum supports the lack of documentation of the derabucca by stating, "The history of the doumbek is not well 
documented and ripe with conjecture." " Issam Houshan concurs by stating that depending upon geographic region and specific location, the name, drum size, construction, and techniques for the instrument vary. ${ }^{7}$ In his article The Arabic Doumbek, derabucca artist Jamal Mohamed states that although scholars are uncertain where this drum type was first made, it is known to be of ancient origin. ${ }^{8}$ Gust Aspiotes provides the most descriptive account of derabucca history in his text Learn to Play the Dumbeg. According to Aspiotes, the derabucca can be traced to ancient Egypt in approximately 5,000 B.C. based on the study of artifacts and temple paintings found in Thebes and other cities. It is believed, based on the scarcity of derabucca in artwork, that the drum was used by religious leaders as a ceremonial drum on special occasions. Over time, the instrument's popularity spread to Egyptian peasants and gradually throughout Africa and the Middle East. $^{9}$

The most prominent books on the history of percussion include John H. Beck's Encyclopedia for Percussion, Jeremy Montagu's Timpani and Percussion, and James Blades' Percussion Instruments and Their History. These resources briefly discuss the history of the derabucca. John H. Beck's Encyclopedia for Percussion is a comprehensive resource covering all of the major percussion instruments, but while percussion instruments from Brazil, the Caribbean, Latin-America, and India are presented and discussed in detail, the derabucca and other similar goblet shaped drums from North Africa and the Middle East are only defined and a list of additional names for the instrument is given. Jeremy Montagu's Timpani and Percussion traces the history and developments of percussion instruments from their origins to the present

\footnotetext{
${ }^{6}$ The Art of Arabic Drumming: Taught by Trevor Salloum, prod. and dir. Jiri Bakala, 43 min., Mel Bay Publications, 2007. Dvd.

${ }^{7}$ Introduction to Middle Eastern Rhythms with Issam Houshan, Bellydance Superstars, 2009. Dvd.

${ }^{8}$ Jamal Mohamed, “The Arabic Doumbek," Percussive Notes 48 no. 5 (2012): 20.

${ }^{9}$ Gust Aspiotes, Learn to Play the Dumbeg, (Hollywood: Try Publications, 1977), 1.
} 
day and while there is a chapter designated for world percussion including a variety of instruments presented in this text, the derabucca is only briefly mentioned. In James Blades' Percussion Instruments and Their History, there is a chapter designated to discuss the instruments of Mesopotamia and Egypt, however the discussion concerning the derabucca is limited to construction and regional size differences.

\section{Performance and technique}

Jeremy Montagu states "Like all true high-art drums, the tabla, the various forms of the darabukka, and many frame drums are played with the fingers. With sticks one has a very limited control over tone quality, whereas with the fingers an almost infinite variability and range of sonority is available." ${ }^{10}$ While Montagu's statement may be controversial among percussionists, his statement supports the virtuosity and diverse sonic capabilities the derabucca is capable of producing.

The majority of available written resources concerning derabucca performance practice present fundamental aspects of performance and technique. Introduction to the Dumbek, by Raquy Danziger, Learn to Play the Dumbeg by Gust Aspiotes, The Arabic Doumbek by Jamal Mohamed, The Magnificent Darbuka Rhythms by Mel Bay Publications and Doumbec Delight by Mary McDonald are reflective of the basic resources available. While providing instruction pertaining to basic technique, tone production, hand placement, and fundamental rhythms for the instrument, the bulk of these resources do not discuss advanced techniques.

The most abundant media format that address performance and technique are DVDs. There are several video recordings that serve as a source for emulating posture, positioning, and

\footnotetext{
${ }^{10}$ Jeremy Montagu, Timpani and Percussion, (London: Yale University Press, 2002), 171.
} 
placement of the instrument. ${ }^{11}$ DVDs by Amir Naoum, Issam Houshan, and Trevor Salloum are examples of available resources for learning the basic techniques of the derabucca. Included in these resources are exercises which help build technical facility and finger control while also providing a visual and auditory demonstration of tone production. Generally speaking these materials address basic technique, types of derabucca, exercises, and present a sampling of traditional Middle Eastern rhythms commonly associated with the instrument. However, these resources do not detail advanced musical techniques or ornamentation for the instrument. The majority of these materials do not include the use of the derabucca in a musical context or setting.

While there are numerous resources that provide introductory material, there are only audio or video recordings of advanced performance techniques. The derabucca solo on the CD Ozlem by the group Turku is an example of the virtuosic capabilities of the instrument. ${ }^{12}$ There are also videos available via YouTube that display advanced techniques. One example is an advanced solo by professional performer of Middle Eastern percussion, Yousif Sheronick. This video performance requires technical mastery of the instrument and is a display of advanced technique and musicianship on the derabucca. ${ }^{13}$ While these videos are an important resource, there is a lack of notated materials focusing on complex and highly expressive techniques for the derabucca.

\footnotetext{
${ }^{11}$ The Art of Arabic Drumming: Taught by Trevor Salloum, Mel Bay Publications, 2007. Dvd.; Begintermediate Doumbek Workshop with Carmine T. Guida, Carmine T. Guida, Inc., Dvd.; Doumbek: Technique and Rhythm with Amir Naoum, WorldDance: New York, Dvd.; Introduction to Middle Eastern Rhythms with Issam Houshan, Bellydance Superstars, 2009. Dvd.; The Quick Guide to Playing Doumbek featuring Todd Roach, Carl Fischer: New York, Dvd.

${ }^{12}$ Turku, Ozlem, CD.

${ }^{13}$ Yousif Sheronick, http://www.youtube.com/watch?v=zENRNvFs-rk
} 


\section{Notation and repertoire for the derabucca}

The concept of notating music is predominantly a Western idea. ${ }^{14}$ Around the world, music is successfully shared and disseminated using oral tradition. Written notation is limited in what it can convey and is merely one way of communicating music. In his article, Prescriptive and Descriptive Music-Writing, Charles Seeger discusses the nature and inherent limitations of musical notation. ${ }^{15}$ There is more to music than can be communicated through written notation such as nuance, style, and improvisation.

Derabucca notation is not standardized. There are a variety of systems and individualized written methods of expressing rhythm and sound on the instrument. One example of notation used is presented in derabucca artist Raquy Danziger's article titled Introduction to the Dumbek. In this article the author explains the notational system which is inspired by the Indian bol system and used for the derabucca. "Bol" literally means "word" and represents a syllable used to mimic the actual sounds of the drum. ${ }^{16}$ Danziger has modified this concept and established a system that is based on underlines, each representing one beat. A line with two letters divides the beat in half while three letters divide the beat into thirds. The sounds doum, tek, ka, slap and pop are represented by the letters $\mathrm{D}, \mathrm{d}, \mathrm{T}, \mathrm{t}, \mathrm{K}, \mathrm{k}, \mathrm{S}, \mathrm{s}, \mathrm{P}, \mathrm{p}$, with uppercase letters indicating a loud dynamic and lowercase lettering indicating a soft dynamic. Doum is a deep, bass sound produced by the right hand in a closed position striking near the center of the drum. Tek is a right hand rim hit that produces a higher-pitched sound with the fingers relaxed and in an open position. $\mathrm{Ka}$ is also a higher-pitched sound similar to tek, but is produced by the third finger of the left hand.

\footnotetext{
${ }^{14}$ Randel, The Harvard Dictionary of Music, $4^{\text {th }}$ ed., 570.

${ }_{15}$ Charles Seeger, "Prescriptive and Descriptive Music-Writing," The Musical Quarterly 44 no. 2 (1958): 186.

${ }^{16}$ John Beck, Encyclopedia of Percussion, $2^{\text {nd }}$. Ed., (New York: Routledge, 2007), 180.
} 
Slap is produced by cupping the right hand in the shape of a tent. The pop sound is achieved by producing the $k a$ with the left hand while pressing on the drumhead with the side of the right hand. ${ }^{17}$ Fundamental sounds, technique, and rhythms are presented in the article but advanced musical techniques are not addressed (Figures 1.1 and 1.2).

Figure 1.1. Danziger Notation Example 1

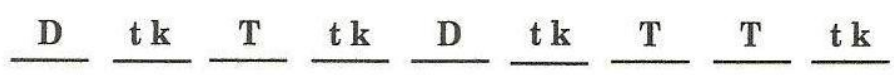

Figure 1.2. Danziger Notation Example 2

\begin{tabular}{|c|c|c|c|c|c|c|c|c|c|}
\hline D & T K & D & $\sim \sim$ & T K & ${ }^{*} \mathbf{K}$ & I & D & $\mathbf{S}$ & T K \\
\hline D & D & D & $\sim$ & $\mathbf{T} \mathbf{K}$ & $* \mathbf{K}$ & I & D & $\mathbf{S}$ & T K \\
\hline
\end{tabular}

Another example of derabucca notation by Jonathan Kessler uses a traditional musical staff indicating the doum and tek sounds with the first and second spaces respectively. Doum and tek are intended to be played using the performer's dominant hand and $k a$ is notated for the nondominant hand. A basic Ayoub pattern with variations is provided below to demonstrate ways of embellishing and filling out various rhythms ${ }^{18}$ (Figure 1.3). Ayoub is a traditional two beat rhythmic cycle commonly used in Arabic music.

\footnotetext{
${ }^{17}$ Raquy Danziger, "Introduction to the Dumbek," Percussive Notes 43 no. 5 (2005): 44.

${ }^{18}$ Jonathan Kessler, "Turkish and Armenian Rhythms for American Drummers." Percussive Notes 33 no. 3 (1995): 39.
} 
Figure 1.3. Kessler Notation Examples

\section{Example 1. Ayoub (Basic)}

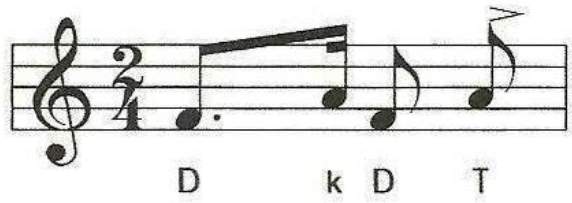

Example 2. Ayoub (Variation)

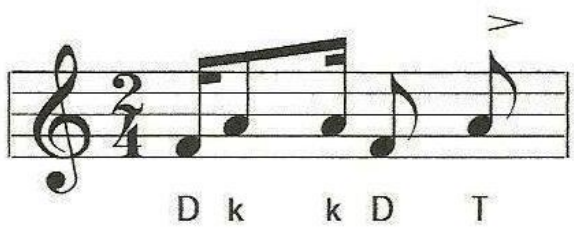

Example 3. Ayoub (Variation)

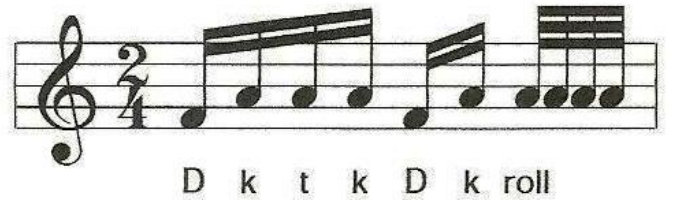

A third example of derabucca notation is presented in Jamal Mohamed's article The Arabic Doumbek. In this example, rhythms are notated using a two line staff representing the doum and tek sounds. Hand-to-hand motion is indicated with " $\mathrm{R}$ " for right hand and " $\mathrm{L}$ " for left. Pitch bending is indicated with " $p$ " for press and "ps" for press and slide to add inflection.

Ornamentation is indicated with hand and finger suggestions ${ }^{19}$ (Figures 1.4 and 1.5).

Figure 1.4. Mohamed Notation Example 1

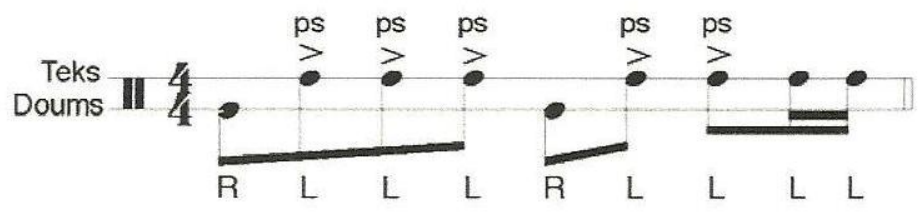

\footnotetext{
${ }^{19}$ Mohamed, "The Arabic Doumbek," 20.
} 
Figure 1.5. Mohamed Notation Example 2

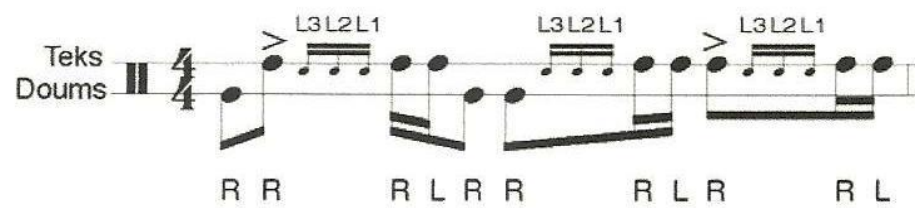

A fourth example of derabucca notation is found in Dr. Anthony Di Sanza's Concerto for Darabukka and Percussion Quartet. A traditional five-line staff is used to notate the doum and tek sounds in this work. Doum is performed with the right hand and tek is performed with the left and/or right hands. The majority of the notation represents only the most basic framework of each rhythmic cycle. Although basic notation is used, Di Sanza's concerto is an example of a work that is pushing to advance the status of the instrument as it is one of few concerti for the derabucca. (Figures 1.6 and 1.7).

Figure 1.6. Di Sanza Notation: Derabucca Key

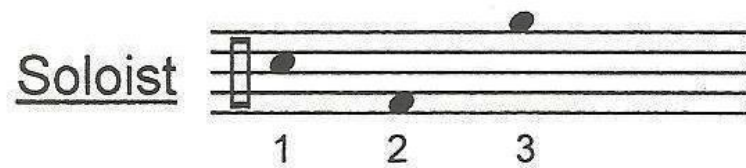

\section{Tek (left and/or right hands)}

2. Doum

3. Suspended Cymbal

Figure 1.7. Di Sanza Notation in Context

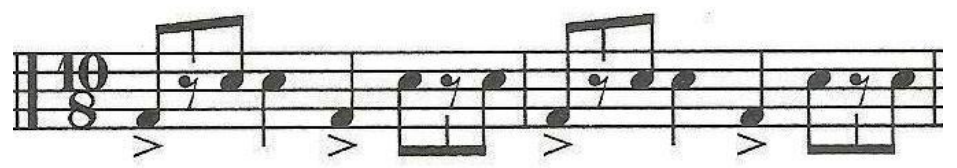

In this work the performer is free to make many of the interpretive decisions as it requires extensive improvisation by the soloist. Di Sanza states, "The soloist is to create the solo part through stylistic understanding and personal creativity. Given the music style, improvisation is 
essential. The soloist is strongly encouraged to think and plan carefully regarding the internal structure of each section in the composition and their relationships to the composition as a whole." ${ }^{20}$ Di Sanza's concerto explores three Middle Eastern rhythmic cycles and calls for a variety of derabuccas to be used by the soloist throughout the performance. The soloist is supported by a combination of traditional instruments from the Middle East, Eastern Asia, South America, and the Caribbean.

Few other composers have published works specifically for the derabucca, as it remains largely unexplored in the Western percussion world. Outside the repertoire of Halim El-Dabh and the concerto by Dr. Anthony Di Sanza, there is limited published repertoire for this instrument. Dr. Scott Herring provided a review of Di Sanza's Concerto for Darabukka and Percussion Quartet in the February 2008 issue of Percussive Notes, the scholarly journal of the Percussive Arts Society. "This is an exciting new work in an uncommon genre. There is a noticeable lack of works that feature hand drums in a "concerto" environment." ${ }^{21}$ Herring's review supports the shortage of literature for the derabucca and hand percussion.

El-Dabh's works make a dramatic departure from the aforementioned systems with his elaborate notational style. However, even with a large amount of detail in notational instruction, his system has limitations. Charles Seeger uses the terms "prescriptive" and "descriptive" to categorize various levels of notation. As defined by Seeger, prescriptive notation is when the composer provides specific instruction to guide the performer's interpretation and execution of the work. Descriptive notation is when the composer provides instruction about how the music

\footnotetext{
${ }^{20}$ Anthony Di Sanza, Concerto for Darabukka and Percussion Quartet (Everett, PA: HoneyRock, 2007), liner notes.

${ }^{21}$ Scott Herring, New Percussion Literature and Recordings, review of Concerto for Darabukka and Percussion Quartet, by Anthony Di Sanza, Percussive Notes, 46, February 2008, 70.
} 
should sound. Halim El-Dabh's works for derabucca utilize both prescriptive and descriptive elements, but his works appear to show a progression from prescriptive in his early works to a descriptive notational approach in his more recent works.

El-Dabh's notational system differs from the above-mentioned types in that it includes detail that is not addressed in other notational systems. Sonic No. 7 and No. 10 is an example of the detail present in El-Dabh's writing for the instrument. Composed early in El-Dabh's career, Sonic No. 7 and No. 10 utilizes a unique notational system that gives specific instruction concerning fingering, positioning and shape of the hands, amount of resonance, pitch bending, and methods of striking the instrument (Figure 1.8).

Figure 1.8. El-Dabh's Notation in Context: Sonic No. 7

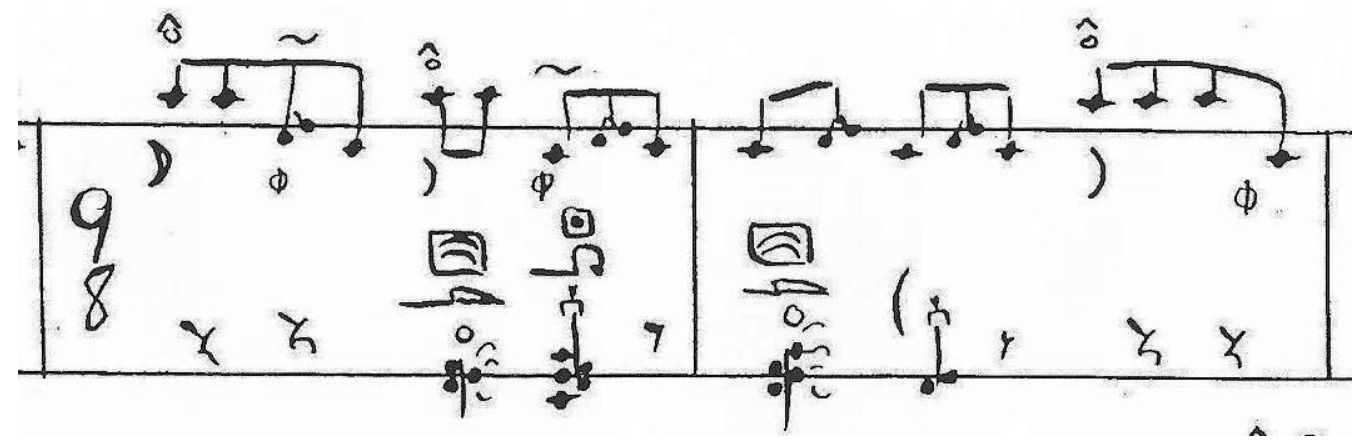

Other more recent works by El-Dabh such as The Miraculous Tale and Sweet and Prickly Pear use elements of this system to communicate desired sounds and effects but differ in that the notation is more descriptive and less prescriptive in nature. Each work demonstrates the evolution of El-Dabh's notation for this instrument and implications for musical interpretation (Figures 1.9 and 1.10). 
Figure 1.9. El-Dabh's Notation in Context: The Miraculous Tale (saxophone top system, derabucca bottom system)

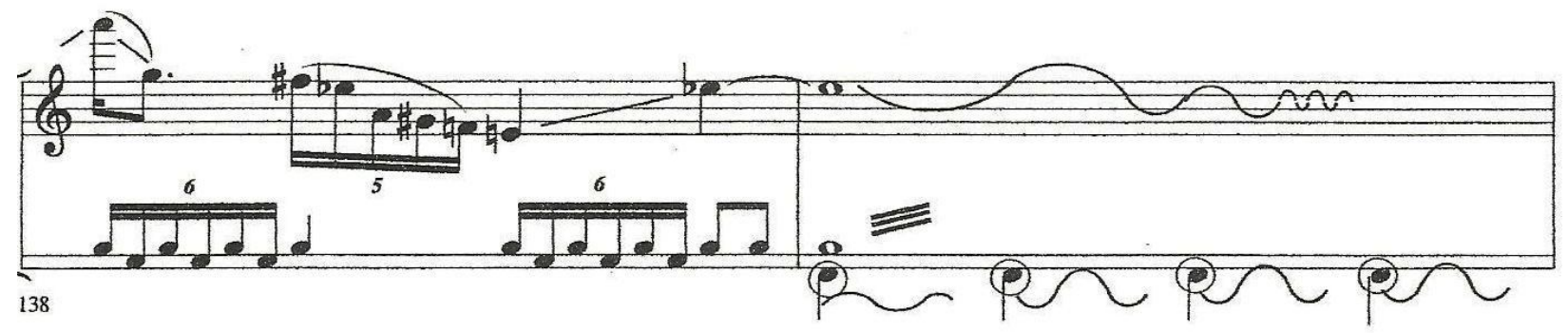

Figure 1.10. El-Dabh's Notation in Context: Sweet and Prickly Pear (violin top system, derabucca bottom system)

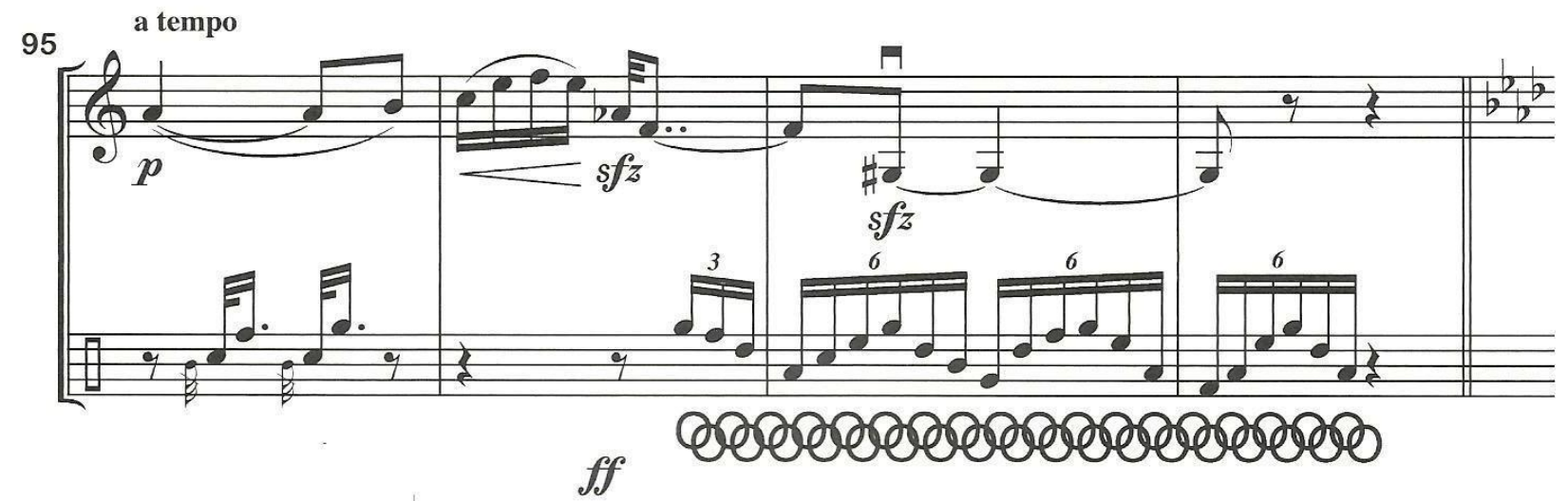

The previous notational systems represent a wide range in methods of notation and require varying degrees of music reading ability needed by the performer. There are several additional resources that provide varied notational approaches in expressing the sounds of the derabucca, however, these notational systems are more fundamental in nature and do not introduce any new notational elements compared to the systems already described. Examples include Doumbec Delight by Mary McDonald, The Magnificent Darbuka Rhythms by Mel Bay Publication, and Learn to Play the Dumbeg by Gust Aspiotes. 


\section{CHAPTER 2: SONIC NO. 7 AND NO. 10}

Halim El-Dabh began composing Sonic No. 7 and No. 10 in the early 1960s as he was preparing for his travels to Switzerland and Ethiopia. His natural emotions as he anticipated travel were reflected in the music. ${ }^{22}$ Interestingly, the numbers in the title do not indicate a succession of works. El-Dabh selected the numbers because he felt that they captured the sound, emotion, and feelings he had at the time he composed the work. During this period in his life, ElDabh related the feelings of action, demand, anticipation, reaching out, and restlessness to the number seven while the number ten provided a feeling of balance, content, and resolution.

The word "sonic" is used in the title to relate to reverb, the available vibration, and the processes of exploring the nearly limitless sound possibilities of the derabucca. El-Dabh describes this notion as being similar to a potter working clay; the possibilities of the artist are endless. Each artist uses his or her own unique voice and interpretation to shape the music. According to El-Dabh, the performer has the opportunity to contribute a great amount of personal creativity to the work. For a serious performance, and to capture the effect and intention of the piece, El-Dabh recommends performing both movements with Sonic No. 7 preceding Sonic No. 10 , supporting the natural sense of tension and release to the work. ${ }^{23}$

Sonic No. 7 and No. 10 is the most prescriptive and detailed of El-Dabh's writing for derabucca. The work utilizes the five facets of El-Dabh's unique notational system creating a detailed method of realization for the performer. The five facets of El-Dabh's notation include instruction and detail concerning placement, position, resonance, fingering, and touch. Each facet

\footnotetext{
${ }^{22}$ Halim El-Dabh, interview by author, telephone conversation, Kent, Ohio, 7 December 2013.

${ }^{23}$ El-Dabh, interview, 7 December 2013.
} 
has additional levels of specificity associated with it, and when combined, serves as a foundation for developing the technique required to perform this work. The piece stems from the Egyptian classical tradition and is El-Dabh's contemporary approach to expressing the sound of the derabucca. The notational system, developed specifically for this piece, is the most ornate and visual of El-Dabh's writing for the instrument. Intricate images are used to express sensitive and delicate aspects of the music to the performer. Through symbols, he has created a visual form of communication, designed to express desired sound and musical intention.

To aid the interpretation of Sonic No. 7 and No. 10, El-Dabh provides a brief explanation at the beginning of the work in order to decode the symbols and notation. He recommends the performer consult his separate publication The Derabucca: Hand Techniques in the Art of Drumming which explains the notational system and five technical components used for this piece. Mastery of these components will allow the performer to fully achieve the musical potential of the work. In addition to discussing the five facets in this booklet, El-Dabh provides a description of the instrument's anatomy, area designations, and measurements of the drum to clarify instruction regarding performance technique.

Sonic No. 7 and No. 10 has a two-line staff in the derabucca part indicating the right hand on the upper staff and the left hand on the lower. Each line is supported with a variety of symbols, each representing a different facet of sound desired. A single note requires simultaneous execution of multiple facets, creating an ever-present challenge for the performer attempting to conceptualize this unique notational system. Figure 2.1 is an example of the staff, notation, and includes indications from each of the five facets which will be discussed in further detail throughout the chapter. 
Figure 2.1. Five Facets in Context (m. 1)

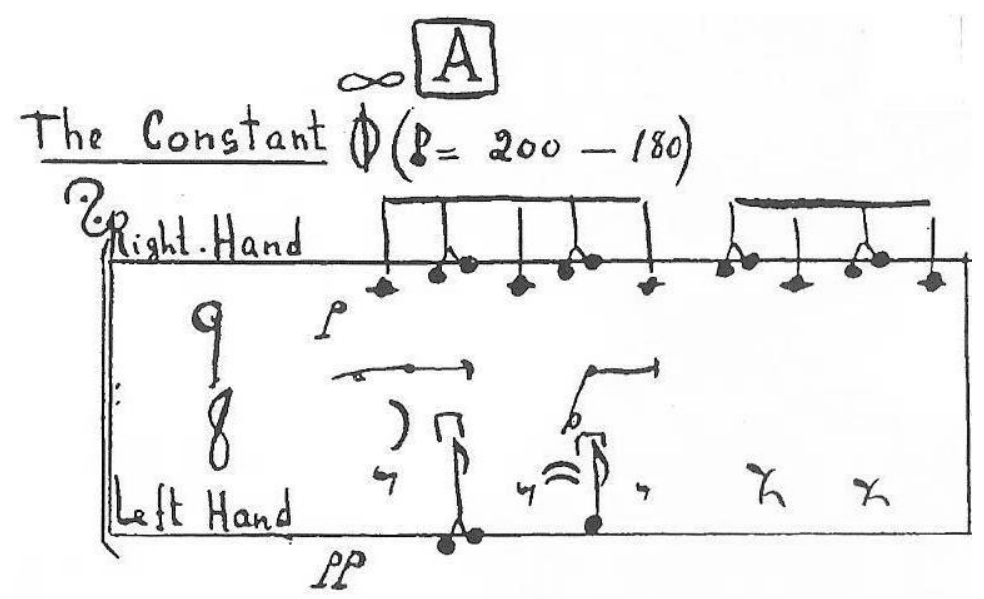

A firm understanding of each of the following facets has an important impact on the performance of Sonic No. 7 and No. 10. Each component must be examined and practiced individually before successfully applying the concept to the work. This section will describe each of El-Dabh's five facets of derabucca performance which include placement, position, resonance, fingering, and touch.

\section{Placement}

The first facet, "Placement" has seven varying degrees pertaining to where the fingers should be located on the drumhead. Below are the available symbols used to indicate the spectrum of placement possibilities. El-Dabh provides an illustration of placement designations in his booklet, The Derabucca: Hand Techniques in the Art of Drumming (Figure 2.2). The letter $\mathrm{V}$ represents the hand in a resting position and the letter $\mathrm{W}$ represents inserting hand in the bell of the derabucca. 
Figure 2.2. Placement Designations

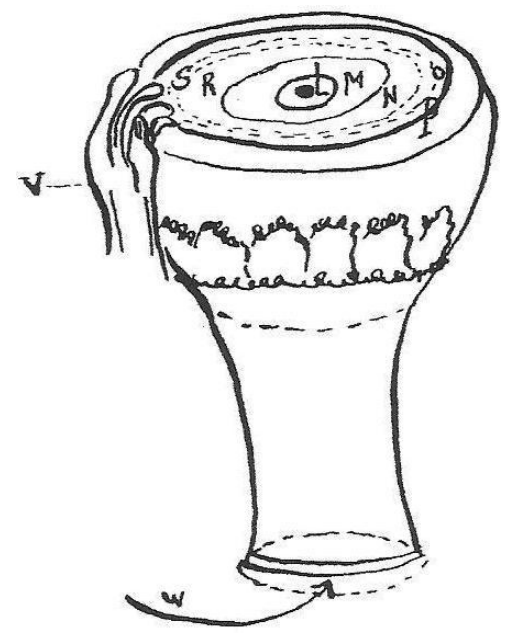

Finger placement ranges from the center of the drumhead to having the finger placed on the rim over the edge. Figure 2.3 designates placement in the center proper, or the very center of the drumhead. This location of the head will provide the fundamental tone of the drum but with few overtones present, which is similar to the nodal point found on timpani or a snare drumhead. Figure 2.4 indicates the center area. This placement is just off of the nodal point, still achieving a dry sound, but with a slight degree of resonance.

Figure 2.3. Center Proper (L)

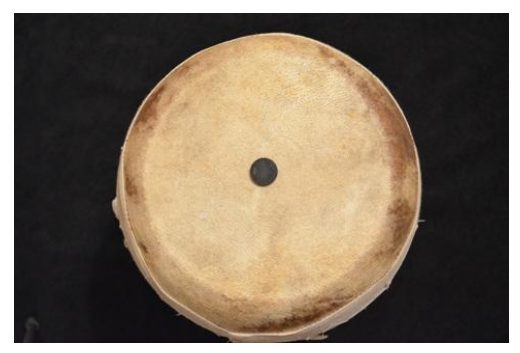


Figure 2.4. Center Area (M)

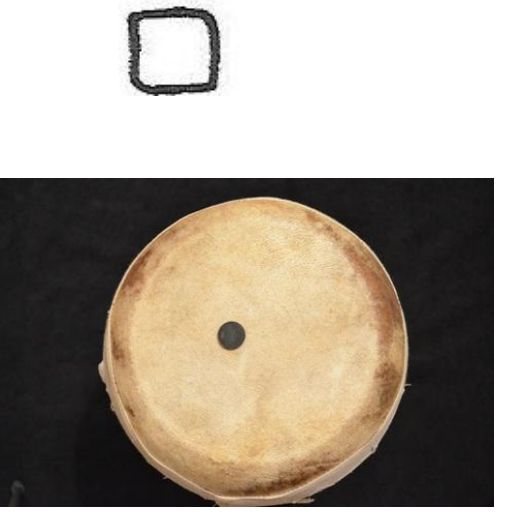

Figure 2.5 designates the area that El-Dabh refers to as "play area." The playing area allows for the fullest level of resonance and overtones to be present and is considered to be halfway between the center of the drumhead and the rim.

Figure 2.5. Play Area $(\mathrm{R} \& \mathrm{~N})$

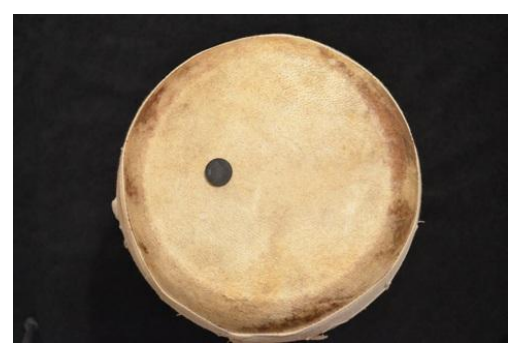

Figures 2.6 through 2.8 relate to rim placement. These areas of the drumhead will be lighter and thinner when compared to the sound achieved from the playing area. The Rim Area is the next position of placement towards the rim (Figure 2.6). In this area, the sound will begin to thin but there is still a level of resonance present. The Rim Proper, (Figure 2.7) is as close to the 
rim as possible without hitting the rim. This will be the thinnest sound of the designated placements on the drum. Rim over the Edge, (Figure 2.8) designates the finger to be used simultaneously over the rim and edge of the drumhead. This placement will result in a thin sound with the upper partials most prominent.

Figure 2.6. Rim Area (S)

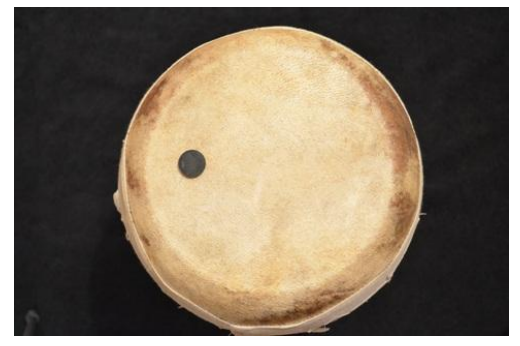

Figure 2.7. Rim Proper (O)

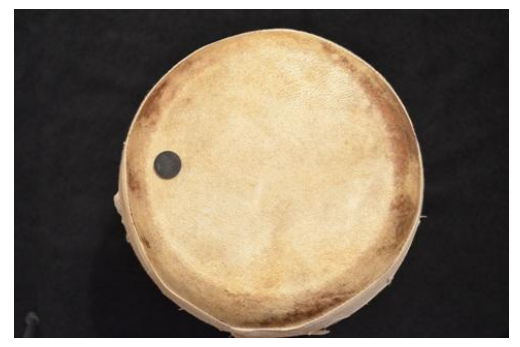


Figure 2.8. Rim over Edge (P)

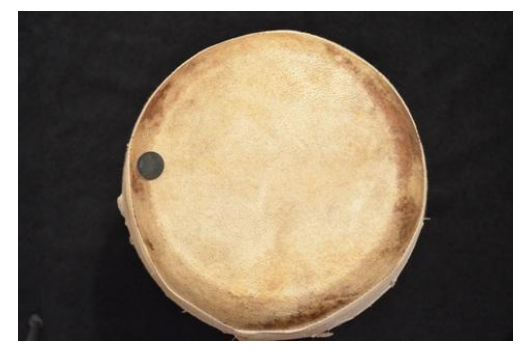

Action of the hands from rim to center, Figure 2.9, is the last symbol under the facet "Placement" and notates an inward or outer motion from rim to center or vice versa. This symbol covers the spectrum of all of the placement options. In general, playing toward the center of the drum will result in more fundamental tone, while playing toward the rim will cause more overtones to be present.

Figure 2.9. Action from Rim to Center

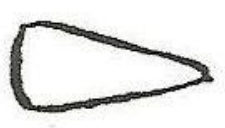

When conceptualizing these varying placement options it is important to remember that each change in placement is subtle and should be adjusted according to the response of the drum. Naturally, there are many factors that will influence the sound of the instrument, from size and shape, to the tension of the head. El-Dabh recommends using a ceramic drum with a fish skin head as this offers the best response, allowing for subtlety and nuance. Once the concept of the 
notation is understood, it is the performer's responsibility to do what he or she can to achieve the various tone distinction. The positions used for one drum may need to be altered in order to achieve similar sounds on another.

\section{Position}

The second facet designed for Sonic No. 7 and No. 10 is "Position." This facet pertains to the relationship of the hands to each other. When establishing the hand relationships, it is helpful to set the drum in its normal standing position and look downward at the head. The notation for this facet is similar to the positioning of hands on a clock, using a center axis on which the hands move in relationship to one another. Once the relationships are understood it is easier to apply them when the drum is in lap playing position during performance. Two figures are provided to establish the concept of hand positioning. There are seven total symbols in this category, each demonstrating various ways in which the hands can be positioned. The right hand is indicated by a short line perpendicular to the stem while the left hand is notated by an open circle off of the stem (Figure 2.10). Figure 2.11 depicts the right hand positioned on the right side of the drum while the left hand is on the bottom part of the drum or the area further away from the drummer. 
Figure 2.10. Position Example 1
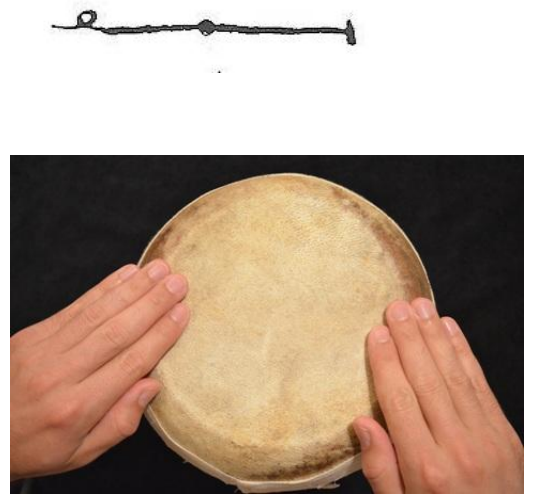

Figure 2.11. Position Example 2
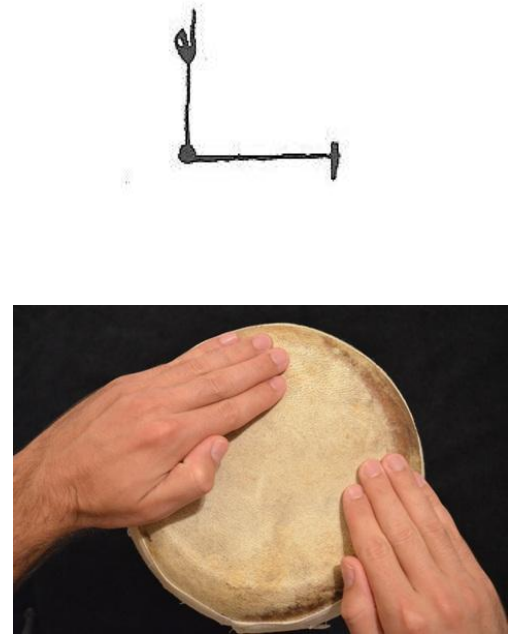

Measure four (Figure 2.12) of Sonic No. 7 is a contextual example of how this concept and notation is applied in various positions. The "position" notation is utilized in the left hand (bottom line). The fingering and placement facets of the bottom line are not altered as the position changes. This example shows the visual element incorporated into the work. 
Figure 2.12. Position in context (m. 4)

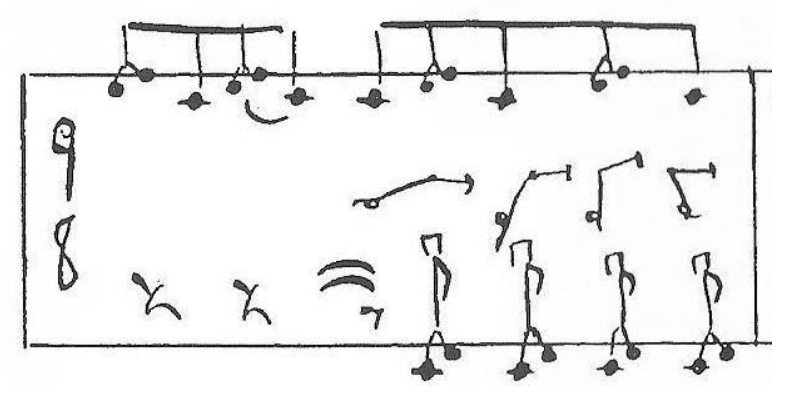

\section{Resonance}

The third facet of El-Dabh's notation system is "Resonance." This facet focuses on the overtones and the various qualities of sound that can be achieved. Notation for this facet consists of five degrees of resonance ranging from a full to dry sound. The fullest sound is intended to have the fundamental and overtones audible (Figure 2.13), while at the opposite end of the spectrum, the sound should be very dry with the overtones most prominent (Figure 2.14). When two symbols of resonance are combined (Figure 2.15), additional nuance is intended and should be added according to the symbol provided. These combinations depend on the performer's interpretation and sound production capabilities. ${ }^{24}$ The intention of Figure 2.15 is to achieve the fullest sound of the overtones. The top line (right hand) of Figure 2.16 is an example of this combination used within the context of the piece. There is a natural comparative relationship between "Resonance" and "Placement." This concept is similar to the relationship between resonance and playing spot on a snare drum and timpani. Playing in the center of the head will result in a dry sound while playing off center will provide a resonant tone. The edge of the drum will achieve a thin sound.

\footnotetext{
${ }^{24}$ El-Dabh, interview, 7 December 2013.
} 
Figure 2.13. Resonance: Extreme Fullness

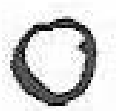

Figure 2.14. Resonance: Extreme Secco

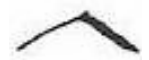

Figure 2.15. Combination of Two Degrees of Resonance

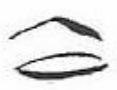

Figure 2.16. Resonance in Context (m. 17)

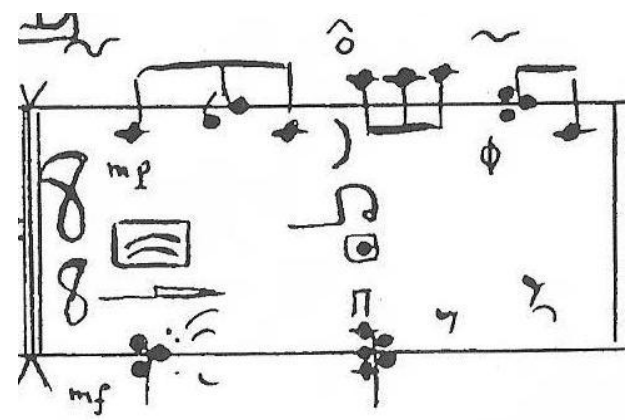




\section{Fingering}

The fourth facet is "Fingering." "Fingering" provides instruction as to which finger should be used and is determined using a single line staff. The middle finger of each hand is designated by the line. The thumb of the right hand is noted a ledger line below and the pinky finger is notated a ledger line above (Figure 2.17). The ordering is reversed for the left hand as shown in Figure 2.18.

Figure 2.17. Fingering: Right Hand

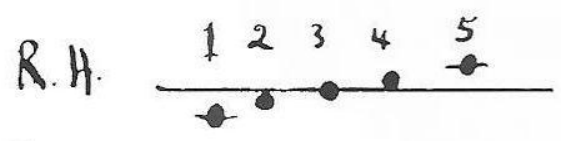

Figure 2.18. Fingering: Left Hand

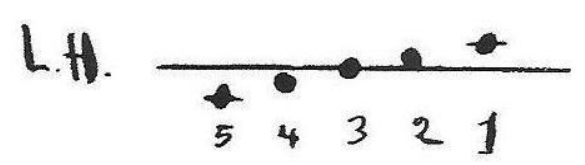

In the piece, there are a variety of finger combinations utilized. Additional symbols and instruction under "fingering" are provided to indicate the use of knuckles (Figure 2.19) and finger snaps (Figure 2.20). These unique articulations provide a change in color and texture. ElDabh states that the hand, wrists, and fingers need to have the strength and dexterity to fully capture the sound distinctions. ${ }^{25}$ Figure 2.19 designates emphasis on the knuckle of the fifth finger while Figure 2.20 indicates the second finger is snapped from the knuckle position. The thumb is represented by the extended line.

\footnotetext{
${ }^{25}$ El-Dabh, interview, 7 December 2013.
} 
Figure 2.19. Fingering: Knuckles

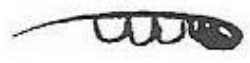

Figure 2.20. Fingering: Finger Snap

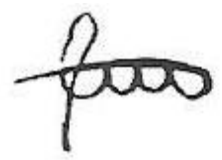

\section{Touch}

The fifth and final facet in El-Dabh's system is "Touch." "Touch" has the greatest number of symbols and instruction pertaining to performance application. Six aspects of touch relate to varying degrees of the curvature of the hand. These range from the hand being completely flat (Figure 2.21) to completely curved so that only the fingertips are touching (Figure 2.22). Measure 25 of Sonic No. 7 shows the notation used within the context of the work (Figure 2.23). This example not only shows the use of multiple facets engaged simultaneously but also two aspects of the facet touch. Located on the last beat of measure 25 in the left hand, the notation indicates both curvature and retention of fingers on the drumhead. This figure exemplifies the detail and prescriptiveness present in the notation for this work. 
Figure 2.21. Touch: Flat Hand

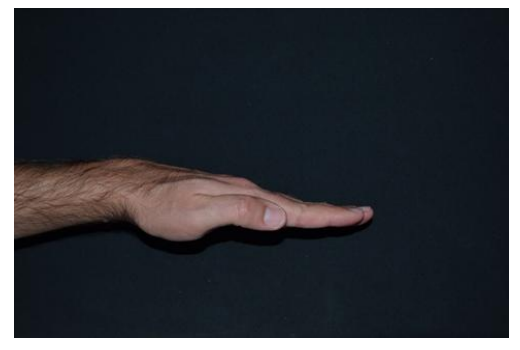

Figure 2.22. Touch: Hand Completely Bent
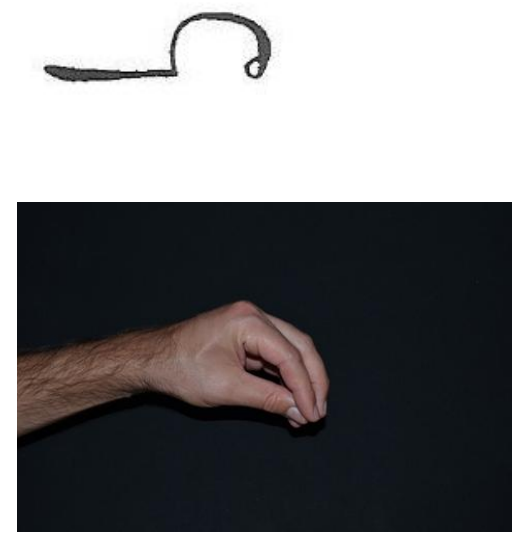

Figure 2.23. Touch in Context (m. 25)

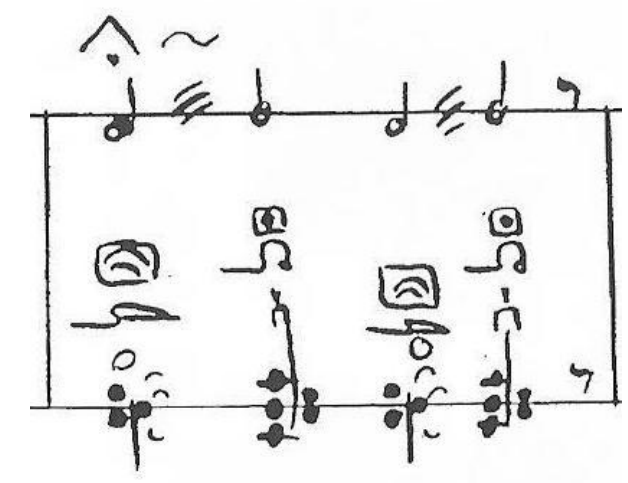


Other aspects of touch relate to articulation. "Attack and release" can be interpreted by a percussionist as a full stroke and is intended to create a full, round sound from the instrument (Figure 2.24). "Touch and retain hand on drumhead" is gently touching the head without audible articulation (Figure 2.25). "Attack and retain hand on drumhead" is considered a dead-stroke, designed to control or shorten the natural sustain of the drum (Figure 2.26).

Figure 2.24. Touch: Attack and Release

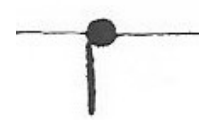

Figure 2.25. Touch: Touch and Retain Hand on Drum

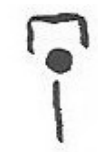

Figure 2.26. Touch: Attack and Retain Hand on Drum

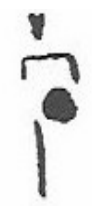

Additional symbols and instruction pertain to sound created by scratching the drumhead with the fingers to provide sustain and change in texture (Figure 2.27). El-Dabh also provides symbols concerning the application of pressure to the drumhead (Figure 2.28). This figure indicates pressure to be applied on the first note and to release the pressure on the second note, resulting in a pitch inflection from high to low. This concept can be applied on the first of a series of notes or on the last of a series of notes. 
Figure 2.27. Touch: Scratch Surface of Drumhead

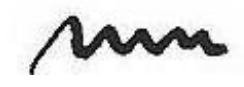

Figure 2.28. Touch: Pressure on First Note and Release on the Second Note

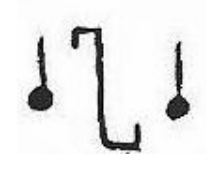

When applying the aforementioned facets into the musical context of the work, it is important for the performer not to be consumed by the minutiae of the notation. While El-Dabh has created an elaborate system based on detail and precision, it is his hope that the notation will serve as a guide for the performer to discover the unique sound possibilities of the instrument. El-Dabh states that in addition to the variable aspects of each facet, it is the rhythmic changes that make melodic expression possible and through the process of realizing rhythms, a melodic impression is created. ${ }^{26}$ More clarity of sound will result in greater tone distinction. In addition to the sonic qualities expressed through his writing, it is El-Dabh's intention to create a thematic and dramatic aspect to the work. El-Dabh's use of thematic material provides a natural sense of growth and development throughout the piece.

\footnotetext{
26 El-Dabh, interview, 7 December 2013.
} 


\section{Performance Suggestion and Interpretation}

\section{Sonic No. 7}

Sonic No. 7 can be divided into three large sections: The Constant, The Variable, and Finale. Each section has a set of thematic and technical characteristics utilized throughout the work. The constant section is the first twenty-seven bars of the piece and can be divided into five smaller sections designated as rehearsal letters $A, B, C, D$, and $E$. When approaching the constant aspect found in the right hand at the beginning of the work, it is important for the hand to be relaxed, resulting in a slight curve to the fingers. This will help with the musical flow, hand movement, and tone production. The amount of the finger pad in contact with the drumhead will also greatly determine how full or thin the sound will be. Bringing out the motives found in the left hand will enhance the melodic impression of the music and create a dialogue between the hands (Figure 2.29).

Figure 2.29. Constant with Left Hand (m. 1 \& 2)

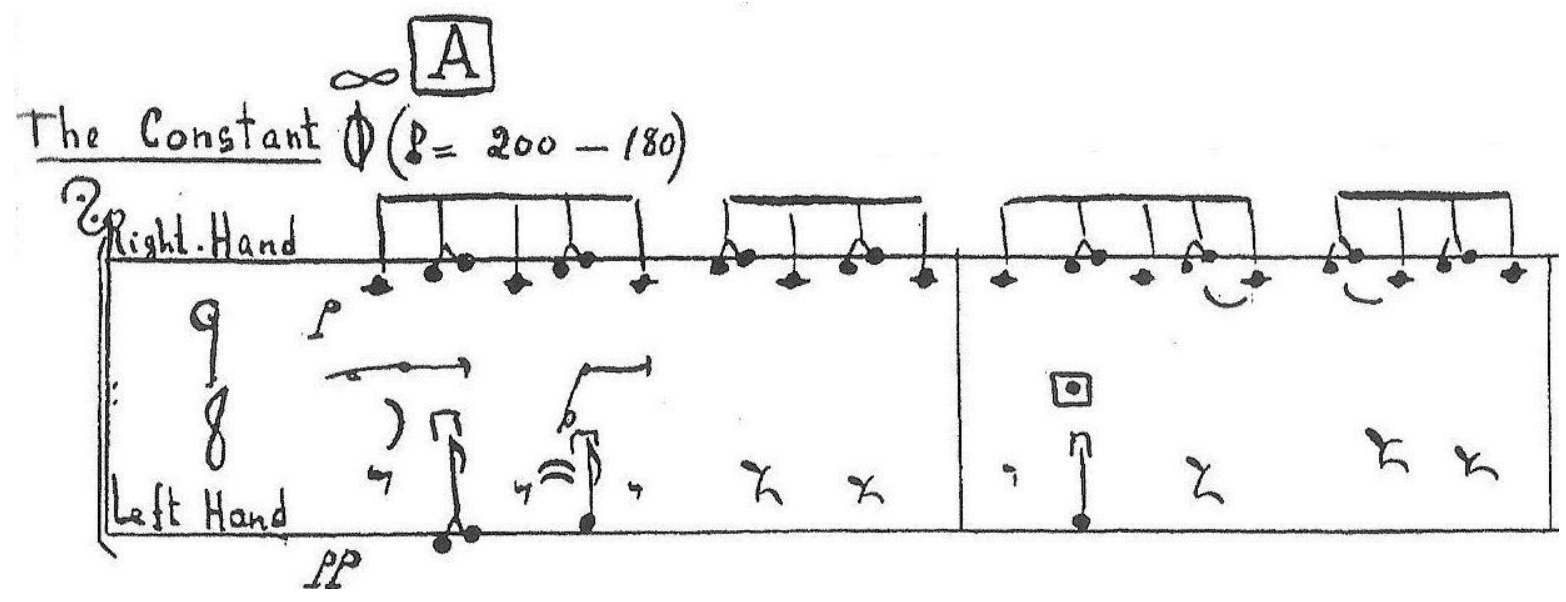


Section $B$ begins with a new and more active figure presented in the right hand (Figure 2.30). The active figure is highlighted while the left hand has its first measure of complete silence. When executing this figure, using the momentum of the thumb stroke along with a flick of the wrist will bring out the sound of the ring finger and provide tone distinction. Also unique to this section is the first use of a finger roll by the left hand in measure eight (Figure 2.31). This figure is a light and delicate interaction with the thematic material of the right hand.

Figure 2.30. Sixteenth Note Figure (m. 7)

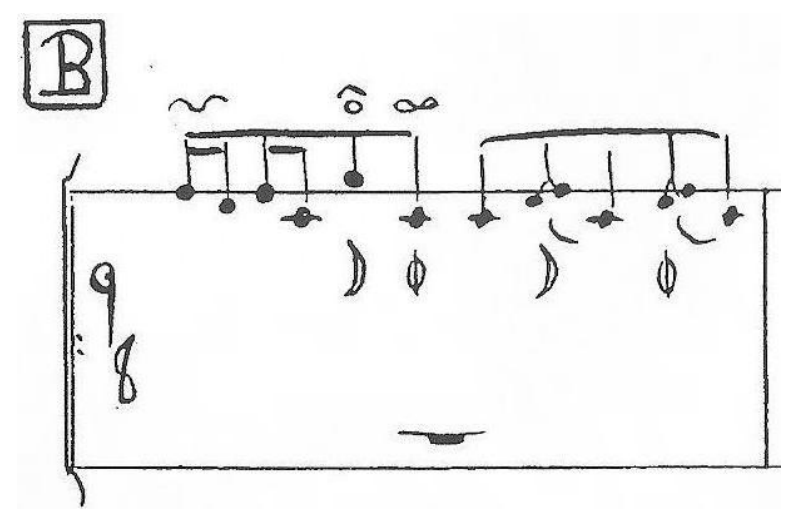

Figure 2.31. Finger roll (m. 8)

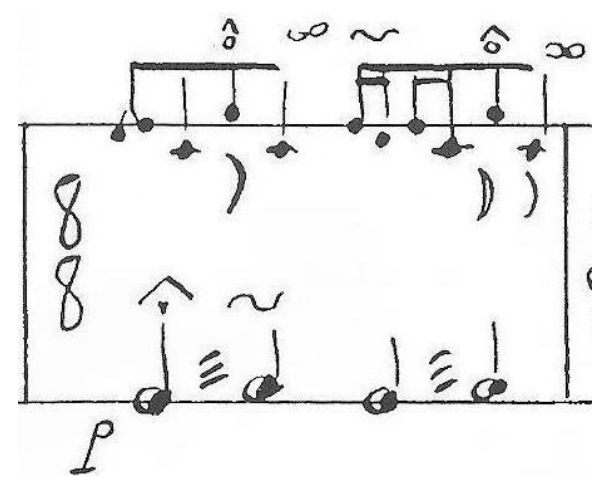


To execute the finger roll effectively, the fingers must be well trained. When developing the facility to perform this technique I found it helpful to use exercises similar to those used in developing a one-handed roll on marimba. Instead of mallet-to-mallet exercises, I used finger-tofinger exercises to develop control, improving my consistency of sound (Figure 2.32). Technical facility should be developed until the finger roll is independent of the thematic material in the left hand. This exercise can be applied to any same-hand finger combination.

Figure 2.32. Finger roll exercise

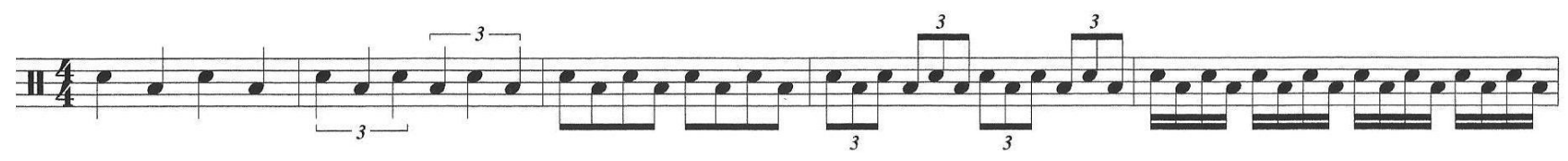

Section $C$ combines elements and ideas from $A$ and $B$, reinforcing the material up to this point. The sonic spectrum expands in section $D$ with the use of the fifth finger towards the rim in the right hand while the left hand is utilizing finger clusters, adding to the impact and contrasting sound distinction (Figure 2.32). There is a dramatic change in the curvature of the left hand that will enhance the sound contrast. When executing the five-note finger clusters in the left hand, it is important to tightly pinch all five fingers together. Adding pressure to the finger cluster in the left hand will help achieve greater distinction of the material in the right hand (Figure 2.33). Section $D$ is the first instance in the composition of more than two fingers being engaged at the same time in either hand, adding to the power and volume of the piece. 
Figure 2.33. Finger Cluster (m.17)
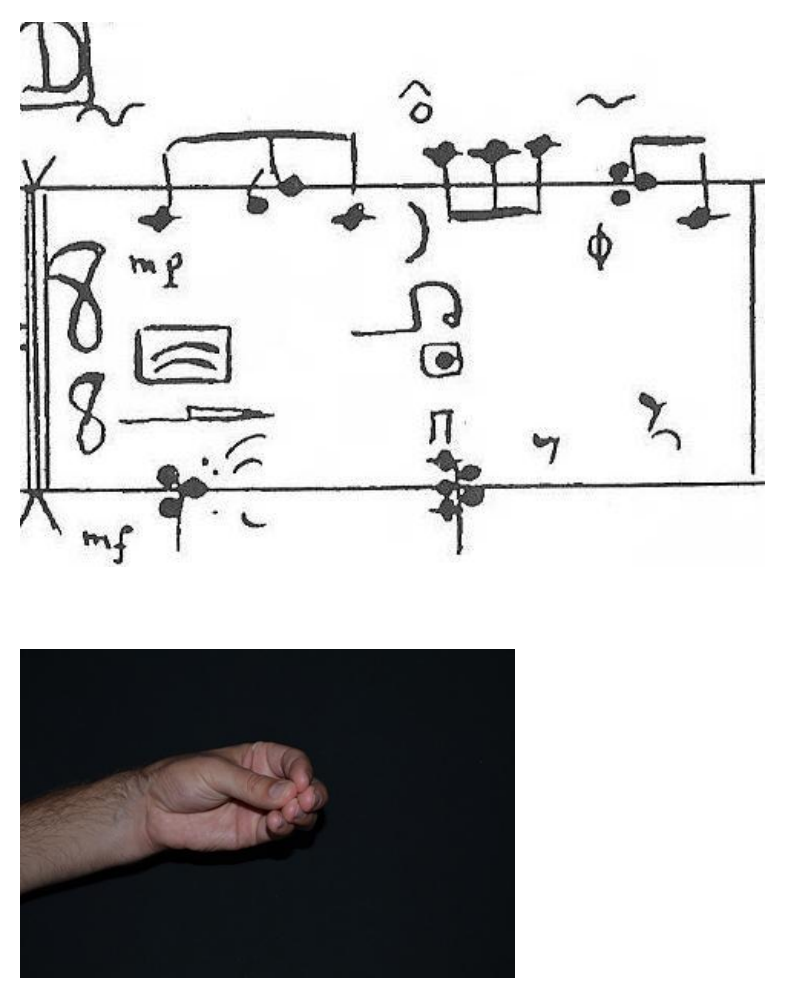

The Variable section is from measure 28 through 48 and includes sections $F, G$, and $H$. It consists largely of finger rolls with recurring thematic material from the constant section. Improvisation is allowed in the Variable section, however free and open soloing is not the composer's intent. Instead, the performer is given the opportunity to shorten, elongate, or manipulate thematic material within the Variable section. ${ }^{27}$

In section $F$, the right hand continues with thematic material from the Constant section while the left hand is executing finger rolls and moving from rim to center (Figure 2.34). This section is also the first to use the finger roll with the thumb and fifth finger rather than the second and third fingers. When the roll utilizes fingers one and five, more rotation of the wrist is needed

\footnotetext{
${ }^{27}$ El-Dabh, interview, 7 December 2013.
} 
when compared to using fingers two and three (Figure 2.34). Keeping the left hand finger roll relaxed will aid in a seamless transition between finger combinations.

Figure 2.34. Rim to Center (m. 30)

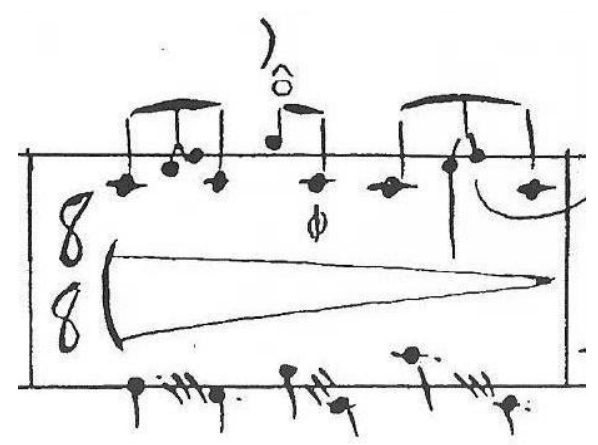

Because Section $G$ is the first section of the work without the constant in the right hand, it naturally lends itself to more opportunities for rhythmic flexibility. In this section both hands are performing various combinations of finger rolls as well as changing placement on the drumhead. These flourishes are the most conducive in Sonic No. 7 for improvisation and embellishment as the concept of hand-to-hand swells can be altered by roll speed as well as movement from center to rim (Figure 2.35). Section H returns to constant material in the right hand with isolated roll figures in the left hand.

Figure 2.35. Finger Rolls and Placement Change (m. 39)

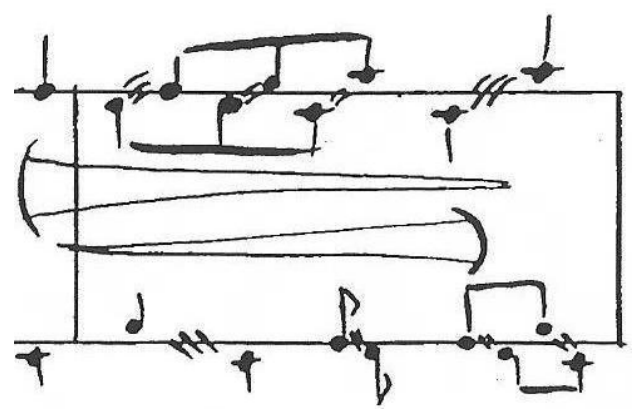


The Finale section is the last twenty-three measures of Sonic No. 7 and includes sections $I$ and $J$. There are two new techniques utilized in this part of the work, both of which focus on bending the pitch of the drum. The first measure of section $I$ notates the first pitch bend with the insertion of the left hand into the bell of the drum (Figure 2.36).

Figure 2.36. Pitch Bend Hand Insertion (m. 49)

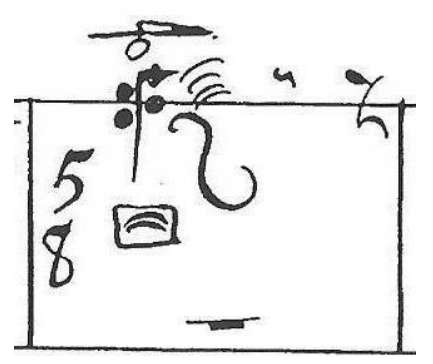

This technique is performed by placing the left hand and forearm inside the drum immediately after striking the drum with the right hand, utilizing the resonance of the drum. It is important that this technique be performed immediately after striking the drum with a quick in and out motion to optimize the tone variation. As the hand and arm move into the drum, the tone will lower. Removing the hand will bring the drum back to its original sound. The further the hand and arm move into the drum, the lower the tone will be. If the hand remains in the drum too long, the full effect of the pitch bend is not achievable. This manipulation of sound results in a low to high pitch bend.

The second measure of section $I$ notates another way to produce a pitch bend. This technique is performed by applying pressure at the beginning of the note and then lessening the pressure throughout the duration of the note. Pressure is applied to the drumhead with the first 
four fingers of the left hand as the right hand executes the notated rhythm. The technique will result in a high to low pitch bend (Figure 2.37).

Figure 2.37. Pitch Bend Hand on Drumhead (m. 50)

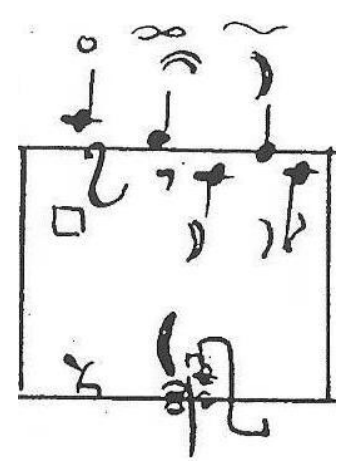

\section{Sonic No. 10}

Like Sonic No. 7, Sonic No. 10 is similarly divided into Constant, Variable, and Finale sections. El-Dabh utilizes a different set of thematic and technical characteristics in this movement of the work. The Constant section consists of the first eleven bars of the piece and can be divided into three smaller sections designated as rehearsal letters $A, B$, and $C$.

The thematic material of the left hand consists of a five-note figure predominantly used throughout the Constant. Within this figure, "Position" is the only facet not indicated. The continuous change in the curvature and placement of the hand not only affects the sound of each note produced, but also contributes as a visual element in this section of the piece. Applying pressure on the last note of this five-note figure on beat five will help expand the melodic impression created in the right hand (Figure 2.38). This is the same concept used in measure 17 of Sonic No. 7 (See Figure 2.33). 
The thematic material found in the right hand is comprised of a combination of eighth and sixteenth note patterns with pressure moving from finger tips to the knuckle position. To execute this technique, pressure is applied on the last note of the measure and released on the first note of the second measure as the fingers slide across the drumhead into the first joint knuckle position. The process of applying and releasing pressure as the fingers change position will result in a brushing sound across the head of the drum (Figure 2.38).

Figure 2.38. Sonic No. 10: Measure 1

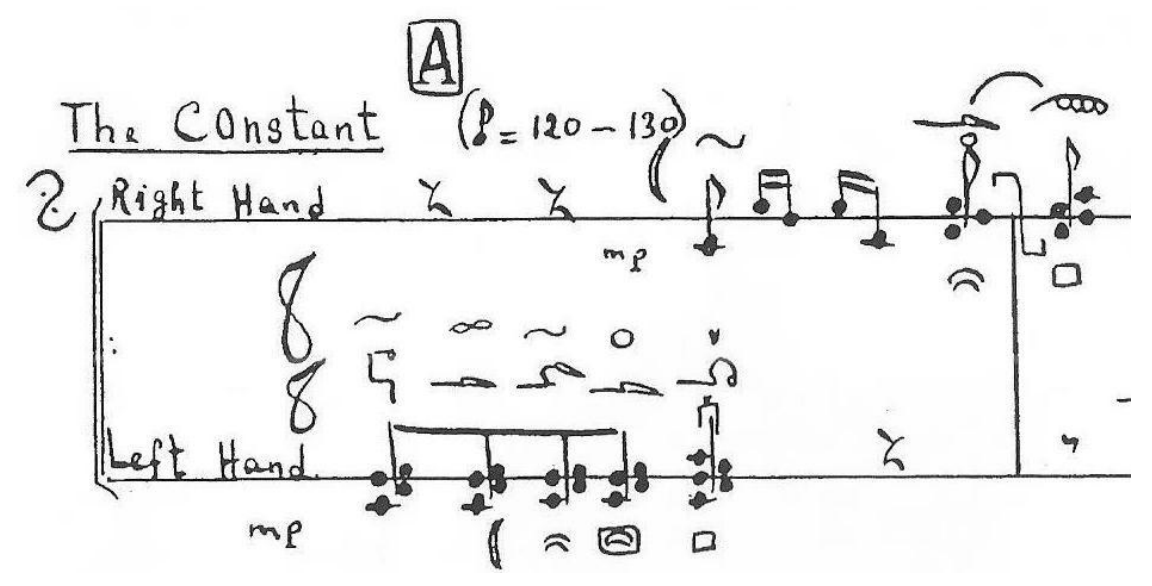

The two-note motive found in the right hand, fourth finger is important as it returns at a later point in the piece and is reemphasized in both hands. The openness of these single finger notes should greatly contrast the sound of the finger clusters. Turning the wrist with a whipping motion will assist in executing the grace note in addition to accentuating the notes in the fourth finger (Figure 2.39). 
Figure 2.39. Sonic No. 10: Measure 7

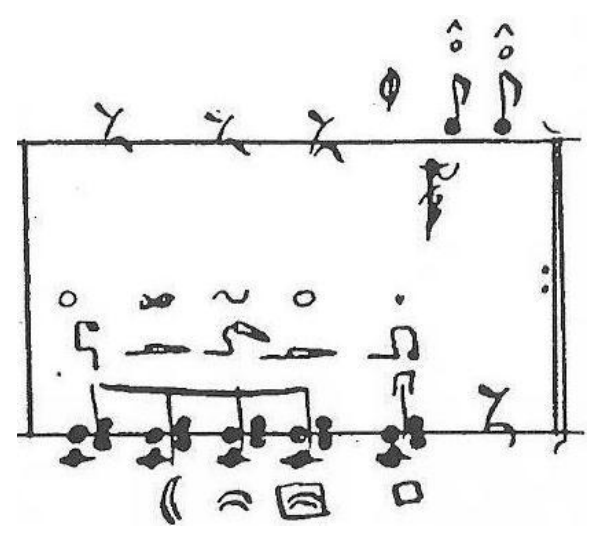

The Variable section is from measure eleven to forty-three and is the largest section of this work. Section $D$ is the first instance where the writing instructs the performer to play handto-hand instead of in an independent manner. The natural movement of the hand-to-hand motion relaxes the feel and creates a sense of balance and resolution intended for Sonic No. 10. Finger clusters are accentuated in the right hand with interlocking eighth notes at a pianissimo dynamic marking. Relaxing the hand and fingers, allowing the hand to move in a whipping motion, will help make a dramatic contrast between the sfzorzando and the pianissimo dynamic markings (Figure 2.40).

Figure 2.40. Sonic No. 10: Measure 15 and 16

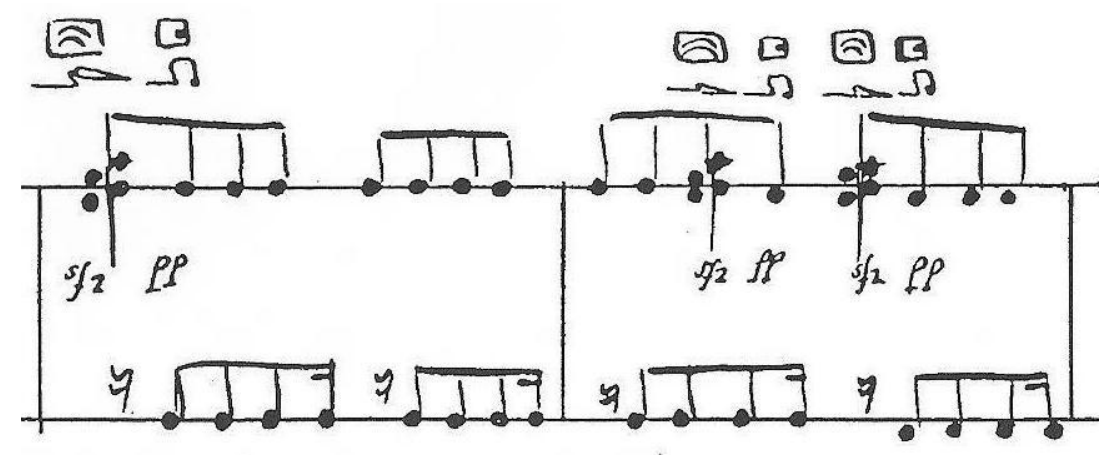


In the first seven bars of Section $E$ the hands and fingers are utilized in an independent nature with both hands reinforcing the open notes played by the fourth fingers, a thematic idea presented earlier in the Constant section of this movement. These two notes, on beats six and seven of measure 26 , should be brought out with intensity and felt as a response to the three and two note groupings in the right hand (Figure 2.41).

Figure 2.41. Sonic No. 10: Measure 25 and 26

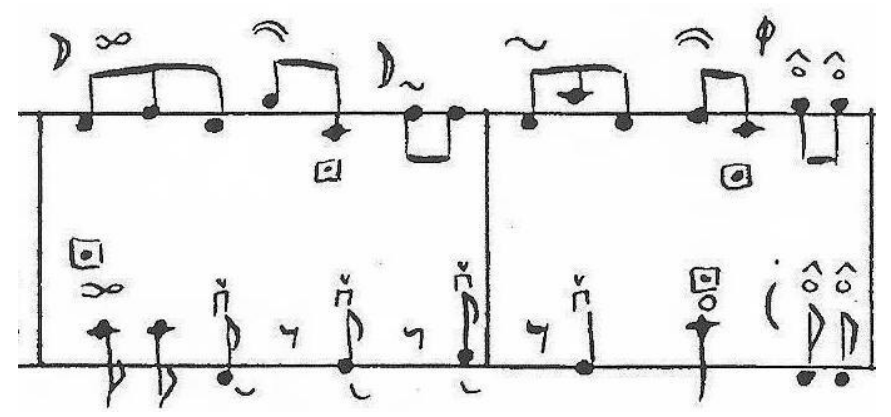

Measures eight through eleven of section $E$ use a combination of thematic elements from sections $D$ and $E$ (Figure 2.42). These measures serve as a transition into the return of hand-tohand motion in section $F$. Section $F$ uses the facet "Position" extensively as there are changes with every grouping, altering the sound and adding a visual element to this section (Figure 2.42).

Figure 2.42. Sonic No. 10: Measure 30 and 31

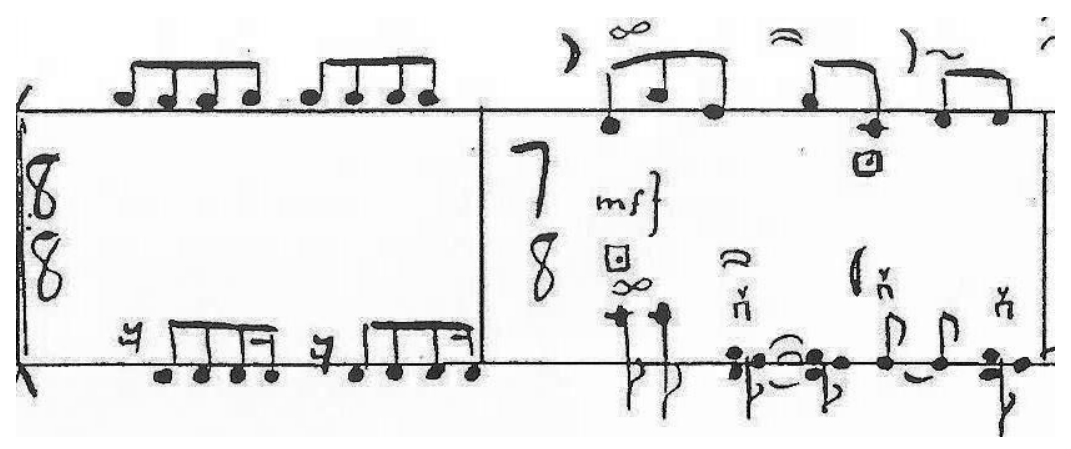


Figure 2.43. Sonic No. 10: Measure 35-37

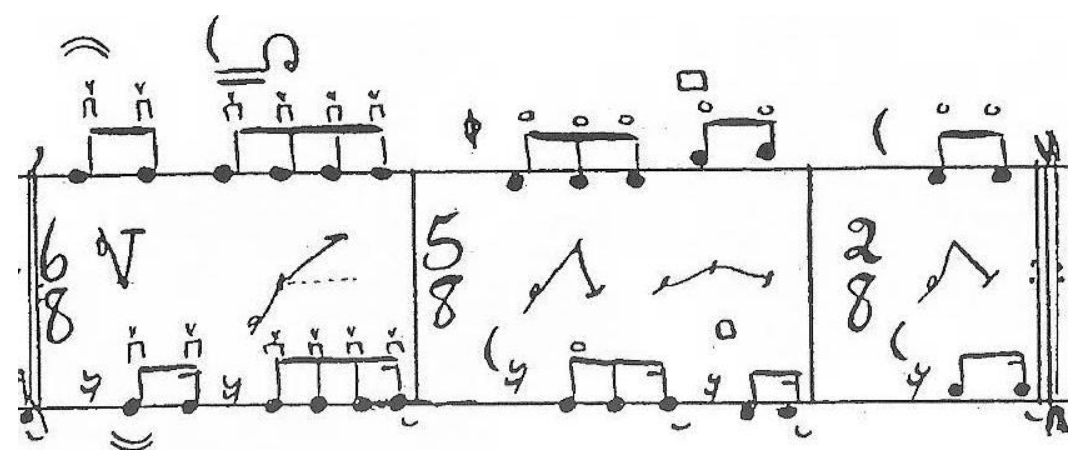

The Finale includes the last eight bars of the piece, uses hand-to-hand motion, and incorporates the use of finger clusters. The clusters enhance the texture, adding volume and density of sound to this last section of the work (Figure 2.43).

Figure 2.44. Sonic No. 10: Measure 45 and 46

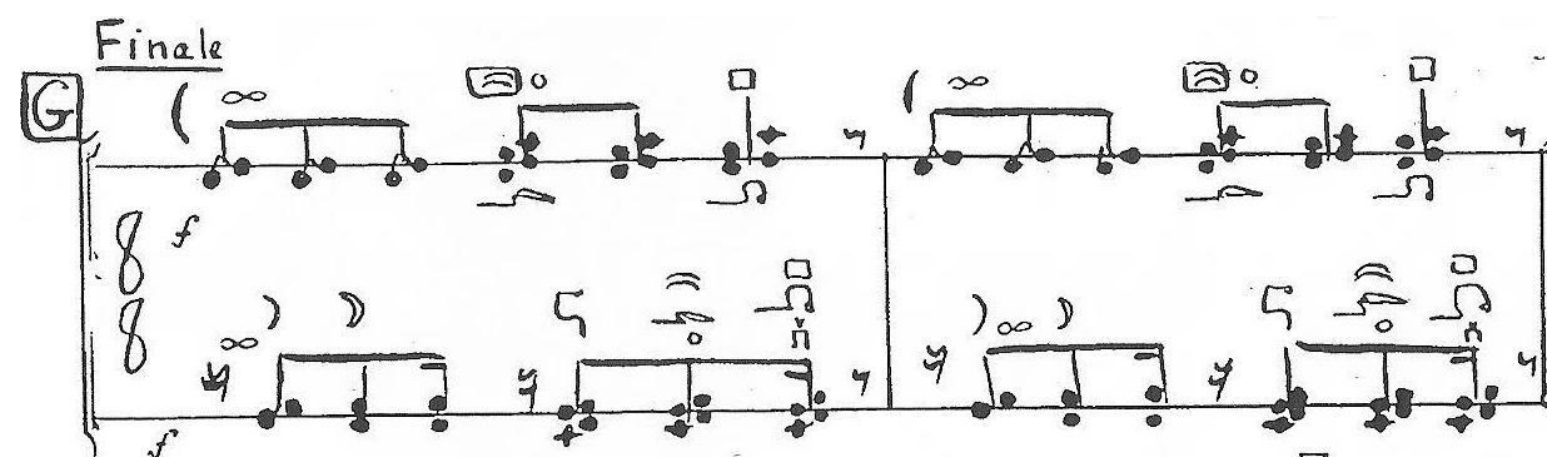

The notation used in Sonic No. 7 and No. 10 represents El-Dabh's most elaborate system for contemporary derabucca music performance. The detailed system gives precise instruction that requires a complete understanding of the entire notational system. When compared to ElDabh's later works, this piece is much more prescriptive in its notational approach. As will be discussed in the following chapters, these later works use a more descriptive notational platform, allowing the performer to make more technical decisions when executing the desired sounds. 
An analysis of Sonic No. 7 and No. 10 reveals that there are musical traits that reflect the ideas of tension and release El-Dabh expressed in the composition of this work. In Sonic No. 7 tension is created at the start of the work by the relentless drive of the rocking motion of the right hand. The quick tempo adds to the sensation of restlessness while there are moments of contrasting sound from the left hand. The gradual but persistent growth in the dynamics contributes to the idea of moving forward while the texture expands with more fingers engaged throughout this section of the work.

From a performer's perspective, the feeling of release in Sonic No. 10 is reflected through the prominent hand-to-hand motion in this section of the work. The natural motion of the hands allows the music to move in a fluid manner. Additionally, the exchange of thematic ideas from the left and right hands at the beginning of Sonic No. 10 adds to the feeling of balance. The relaxed tempo provides a level of comfort for the performer and listener. In interpreting this work I sense these musical features portray the tension and release El-Dabh conveyed when composing Sonic No. 7and No. 10. The following chapters will demonstrate El-Dabh's notational changes from prescriptive to descriptive models. 


\section{CHAPTER 3: THE MIRACULOUS TALE}

Halim El-Dabh's The Miraculous Tale draws from the composer's experience of surviving a lightning strike. During the summer of 1955, as a strong storm approached the Boston area, El-Dabh was outside gathering lawn furniture at his friend's residence in Newton, Massachusetts when lightning struck a nearby table. At the moment of the strike he was physically shaken and emitted a loud scream, which is represented in the work. He recalls being shaky and feeling vibrations throughout his body for close to a month following the incident.

This work consists of three movements titled Lightning ${ }^{28}$, Tenderness, and Stratosphere as each is indicative of the different stages and emotions El-Dabh experienced during this event. El-Dabh explained during an interview that Lightning represents the actual lightning strike that occurred. Tenderness symbolizes the recovery process as El-Dabh was surrounded with thoughts, prayers, and well-wishes from family and friends. The overwhelming amount of positive support greatly impacted his recovery process. Stratosphere represents El-Dabh experiencing the universe from a new perspective, allowing him to go beyond his own mind, spirit, and imagination as a result of this event. The Miraculous Tale is a setting of Halim sharing the story of the event and recovery. ${ }^{29}$

Commissioned by the World-Wide Concurrent Premieres and Commissioning Fund Inc., the work was written in 2006 and premiered on March 4, 2007, El-Dabh's eighty-sixth birthday.

\footnotetext{
${ }^{28}$ Although the movement is titled "lightening" on the sheet music, the composer clarified during an interview that it should read "lightning."

${ }^{29}$ Halim El-Dabh, interview by the author, telephone conversation, Kent, Ohio, March 1, 2014.
} 
The performance took place at Tufts University with Ken Radnofsky performing the alto saxophone and Takaaki Masuko, the derabucca. ${ }^{30}$

\section{Performance Suggestion and Interpretation}

\section{Notation}

Similarly to Sonic No. 7 and No. 10, the derabucca writing in The Miraculous Tale aims to explore the infinite sonic possibilities of the instrument, producing a wide range of tones and timbres from high and delicate, to deep and resonant sounds. The notation for The Miraculous Tale is structured with the saxophone using a traditional 5-line staff while the derabucca is using a two-line staff to designate tone relationships. The sounds of the derabucca in The Miraculous Tale are notated with vocables dum, $m a$, and tak. Vocables are non-translatable words used to imitate musical sounds and serve as a teaching tool. Each vocable represents a continuum of sound ranging from low to high (Figure 3.1). In The Miraculous Tale, El-Dabh's facets of performance are not individually used for each note, but are inherent to the sounds described. In this piece, El-Dabh assumes the performer has a basic knowledge of the sounds and performance of the derabucca. This notation is different compared to Sonic No. 7 and No. 10 where each note is accompanied by individual symbols providing specific instruction regarding placement, position, resonance, fingering, and touch.

\footnotetext{
${ }^{30}$ Halim El-Dabh, The Miraculous Tale (Kent, OH: Halim El-Dabh Music, LLC, 2010), liner notes.
} 
Figure 3.1. Miraculous Tale Notation in Context (m. 1)

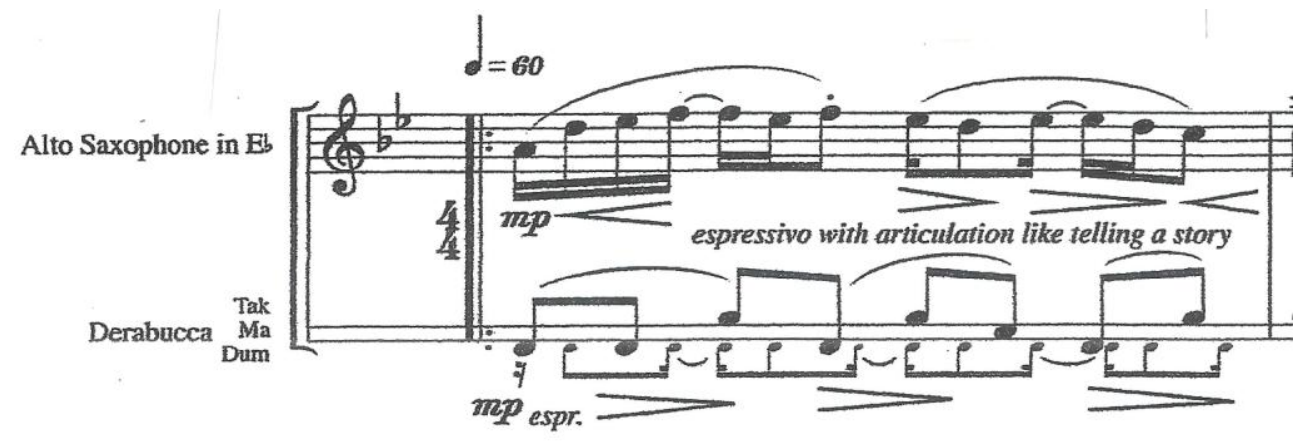

\section{Sounds}

Traditionally, dum is performed using the dominant hand and is the bass sound of the derabucca. To achieve this tone, all of the fingers should be together with the hand straight. The top part of the hand is used from the finger tips to the middle section of the hand. When executing the $d u m$, it is important to use a full open stroke in order to get a full, round, and resonant sound (Figure 3.2).

Figure 3.2. Dum hand position

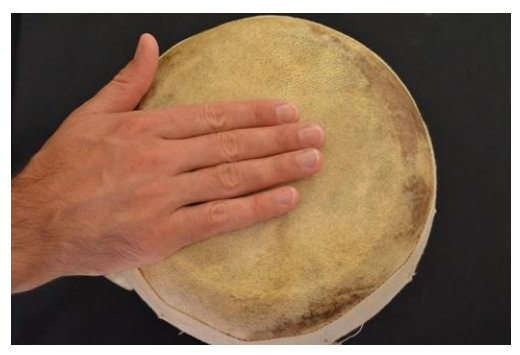

$M a$ is performed using the dominant hand and can use either the tip of the ring finger or the tips of the index, middle, and ring finger combined. The placement should be closer to the edge of the drum than the dum placement, producing more overtones when compared to the dum (Figure 3.3). 
Figure 3.3. $M a$ hand position

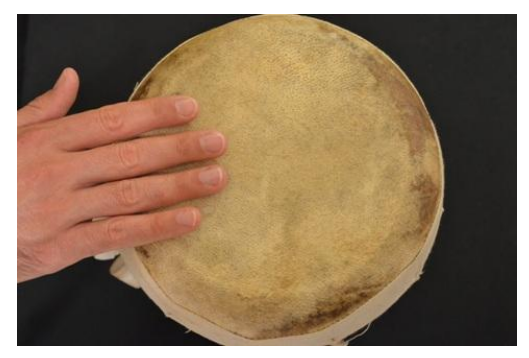

Tak is performed with the ring finger of the non-dominant hand with the finger halfway on the head and rim of the drum. This technique will produce a thin sound with the upper partials most prominent. Depending on relationship of sounds, the hands will need to be adjusted accordingly. The higher tone indications require the performer to play closer to the edge of the drum (Figure 3.4). While the fundamental sounds of The Miraculous Tale are similar to those of Sonic No. 7 and No. 10, the notation of the sounds is the most significant difference between these two works.

Figure 3.4. Tak hand position

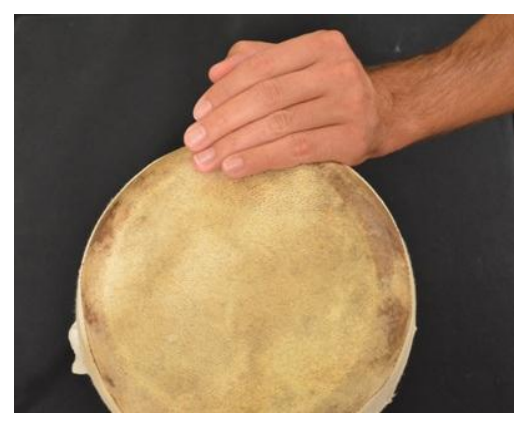

Each of these vocables (dum, ma, and tak) are commonly known among derabucca performers today and serve as the building blocks for derabucca performance. These sounds provide the framework for traditional derabucca rhythms. 


\section{Techniques}

Beyond the primary sounds previously discussed, there are several additional techniques used in this work. These techniques add to the sonic spectrum and enhance the musical expression of the derabucca throughout this piece. The first technique to be discussed in The Miraculous Tale is the use of "ghost" notes. El-Dabh instructs the performer to add ghost notes to the notated skeletal rhythm in the opening section of the piece. These extra notes are intended to add subdivision, subtly, nuance, and embellishment to the outlined rhythm and are a common element found in derabucca performance. Although notated on the dum line, these filler notes can be any of the primary sounds ( $d u m, m a$, and $t a k$ ) and are intended to enhance the groove and contour of the derabucca line (See Figure 3.1).

Retaining fingers on the drumhead is another technique El-Dabh uses in this work. Notated by the use of dashes, this gesture will mute the sound of the note preceding the dash or will give an inflection of the note immediately following. Although it is not indicated, by adding pressure with the retaining finger these musical differences will become more distinct. Measure four of The Miraculous Tale is an example of this procedure resulting in the muting of beat three and the raising of the note on beat four (Figure 3.5). This technique adds to the melodic impression created by the derabucca.

Figure 3.5. Retaining Finger (m. 4)

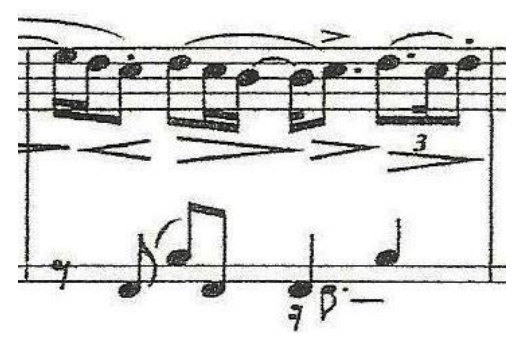


Grace notes are another technique El-Dabh uses in The Miraculous Tale. These embellishments add weight and length to the note. Generally speaking, if the grace notes lead to a dum sound, they are performed with the left-hand (Figure 3.6). If the grace notes lead to a tak sound, they are performed with the right-hand (Figure 3.7). El-Dabh has also notated grace notes that move from tak to dum as well as grace notes that are all taks. Depending on the writing, the performer will need to turn the hand in order to adjust the direction of the finger motion when executing the grace notes.

Figure 3.6. Grace Note Example 1 (m. 9)

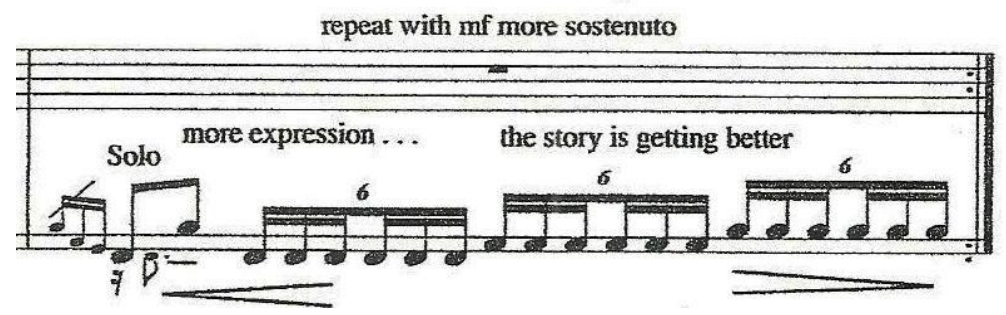

Figure 3.7. Grace Note Example 2 (m.12)

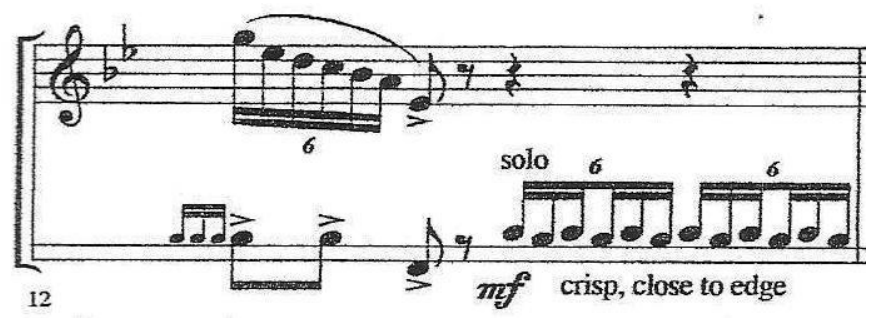

When executing the first beat of Figure 3.6, the grace notes should start near the edge of the drum and move towards the center of the head. After the dum is executed with the right hand, I use the side of my right hand to retain the note. Adding pressure with the right hand will give inflection to the eighth note on the off-beat of beat one performed by the left hand fourth finger, 
enhancing the melodic impression. In this instance, using the side of my hand allows for greater tone distinction when compared to using a finger.

Another technique utilized in this work is the slide with pitch bend. The most effective way to achieve this technique is to perform fast single strokes using the fourth finger of the left hand while the right hand is sliding up the head with the side of the hand along the fifth finger. I found this approach to give the greatest amount of volume and clarity of sound. An example of this technique is used on beat two of measure 14 (Figure 3.10).

Figure 3.10. Slide with Pitch Bend (m. 14)

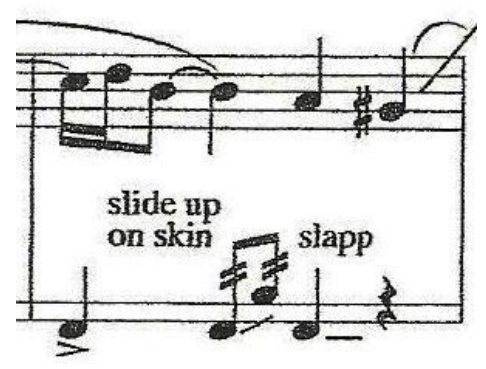

El-Dabh notates another way of creating a pitch bend on the first beat of measure 30 . While the notation is different, it is the same hand insertion pitch bend technique previously discussed in Sonic No. 7 and No. 10 (See Figure 2.35). This technique is executed by placing the left hand in the bell of the derabucca while the right hand strikes the head. Quickly moving the left hand in and out of the bell creates a ripple effect, varying the pitch by creating low vibrations within an octave. The speed at which the left hand is inserted and removed will determine the sound and speed of the ripple (Figure 3.11). 
Figure 3.11. Pitch Bend with Hand Insertion (m. 30)

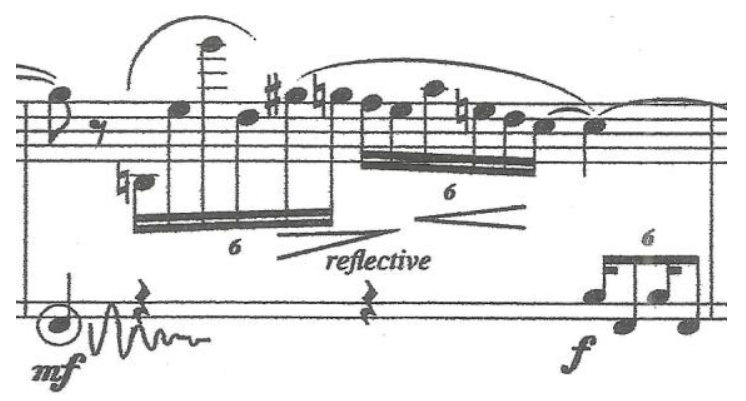

El-Dabh expands the hand insertion pitch bend technique by simultaneously calling for the execution of a one-handed roll (Figure 3.12). This figure also combines two independent techniques previously discussed in Sonic No. 7 and No. 10 (See Figures 2.34 and 2.35). Figure 2.34 is a notated finger roll and Figure 2.35 is a pitch bend via hand insertion. In order for the right hand to produce a strong one-handed roll while the left hand is creating this effect, I found it best to use the thumb and fifth finger of the right hand when performing the roll. Rolling with these fingers is optimized through the wrist motion, allowing for a strong consistent sustain, which enhances the pitch bend (Figures 3.12). Figure 3.13 is another example of a one-handed roll combined with the pitch bend. In this instance the pitch bend will be slower as indicated by the width of waves depicted in the notation of each beat. 
Figure 3.12. One-Handed Roll with Pitch Bend Example 1 (m. 36)

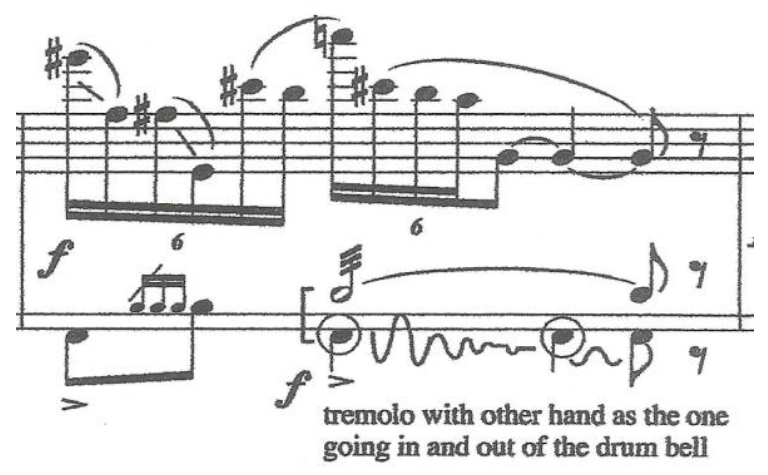

Figure 3.13. One-Handed Roll with Pitch Bend Example 2 (m. 139)

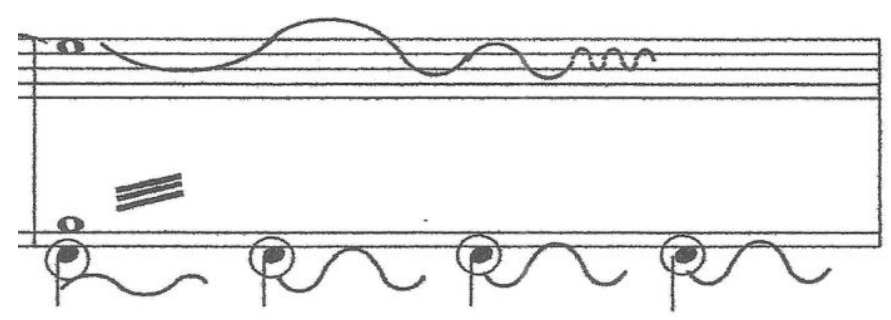

The slap technique is produced by relaxing the dominant hand and letting the fingers move in a whip-like motion striking the center of the drumhead. When achieving the slap, it is important to remember that it is a quality of sound, not a volume. The performer should not force the hand into the drum, but stay relaxed to achieve this sound. The slap is notated on beat three of measure 14 (Figure 3.10). 
Figure 3.10. Slap Technique (m. 14)

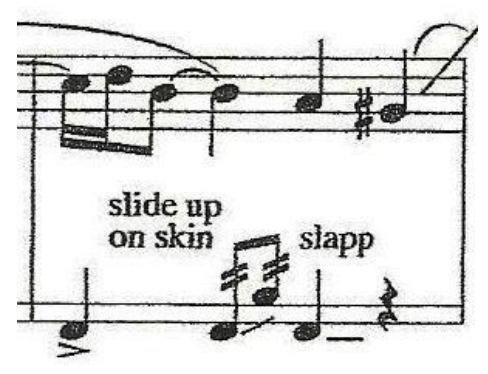

While the notation in The Miraculous Tale is different compared to Sonic No. 7 and No. 10 , the musical and technical elements expressed in these works are very similar. Finger rolls, pitch bends, tone distinction, and retention of fingers on the drumhead are all examples of technical and musical commonalities between these pieces.

\section{Interaction between instruments}

Throughout The Miraculous Tale, the saxophone and derabucca interact in a complementary fashion, exchanging rhythmic and melodic ideas. Both instruments have instances where they serve in an accompanimental, soloistic, or conversational role, and perform similar and contrasting thematic material.

The first movement, Lightning, begins with the derabucca supporting the opening melodic theme of the saxophone. Here the derabucca provides a rhythmic foundation as the saxophone begins telling the story. The ghost notes fill in the constant eighth note pattern of the derabucca, establishing subdivision of the work. These added notes should be lighter in touch and are intended to enhance the outlined eighth-note rhythm. The performer can execute the ghost notes as either $m a$ or $t a k$ sounds. 
Measures 8 and 9 present the first solo passage for the derabucca, exposing the contour and the musical expression of the instrument. This passage should be performed confidently while keeping the hands and fingers relaxed. The sextuplets in the solo passage of the derabucca part imitate the flourishes of the saxophone in the preceding section. Incorporating a flattened finger will provide a deeper tone giving shape and development to the derabucca line. By extending the fingers, more of the finger pad will be in contact with the drumhead. El-Dabh states that the five- and six-note groupings may be played slower or faster as long as they fit into the beat. While the sense of time needs to be maintained, the performer has the liberty to make these figures rhythmically flexible, adding to the interest of the line.

Measure 15-16 and 22-23 highlight instances of call and response between the saxophone and derabucca. In the second measure of the first line, adding pressure with the index finger of the left hand will create a pitch bend, expanding the melodic response of the derabucca to the saxophone. The triplets on the off-beats are performed with the middle and index fingers.

Measures 17-19 showcases an interwoven line between the instruments. The derabucca part should be light and delicately placed in between the sixteenth notes in the saxophone passage. Performing near the edge of the drum will aid in achieving this sound. Rhythmic precision by both performers is needed to create a connecting line between the instruments.

Beat four of measure 30 through measure 39 begins an alternating exchange of contrasting ideas, both dynamically and thematically, between the derabucca and saxophone. Using the weight of the arm will help with the derabucca's strong response to the soft and reflective line of the saxophone. Rolling with the thumb and fifth finger will provide the greatest amount of volume for the one-handed roll for the derabucca in measure 36. As these reactions 
build, measure 39 is a culmination of these thematic ideas, as both instruments are at a forte dynamic level and thematic material is exchanged between them. The derabucca imitates the saxophone material previously used in measure 32 while the saxophone imitates the derabucca material previously used in measure 33.

Measures 48-54 are subdued, as the soft, articulate passage of the derabucca is supported by the long sustaining and reflective line of the saxophone. Keeping the hands close to the derabucca will help to execute the pianissimo passage with clarity and accuracy. There is an abrupt change during the lightning strike, which occurs at measure 55 and requires both performers to execute the fortissimo sixteenth notes with brutal attack. The vocal element "eey," in the same measure, represents the loud scream that El-Dabh emitted when he was struck by lightning. Allowing the hand and fingers to move in a whip-like motion will help bring out the fortissimo rhythms of the derabucca. It is important that the energy level persists through the next several lines of both instruments until the movement closes with a diminuendo and an exchange of imitative ideas between the saxophone and derabucca.

In the second movement, the derabucca has a more rhythmically active and prominent role when compared to the sustaining lines of the saxophone. The extensive use of grace notes and quarter note triplets of this movement provide contrast to the active first movement. The grace notes of the derabucca part should be performed with the tips of the fingers, allowing the performer to achieve the required light and delicate touch.

There are several instances throughout the second movement where the performers have interlocking quarter note triplets such as in measures 77, 79, and 85. Performing these figures with strict rhythmic accuracy will help with the interlocking aspect of both parts combined. 
Often the second triplet grouping of each measure moves in a contrary melodic motion between the instruments. Both instruments must maintain a delicate touch and soft dynamic level to portray the mood of the second movement Tenderness.

Throughout the third movement, Stratosphere, the contrasting groupings of three and two found in the derabucca and saxophone parts depict a feeling of unbalance and question, reflecting El-Dabh's new understanding of the natural world after surviving the lightning strike. Grace notes are the predominant derabucca techniques used throughout the first 39 measures of the third movement and should be performed in a crisp and clear manner utilizing the pads of the fingers. The derabucca consistently performs groupings of three and two while the saxophone shifts and changes more often. There is an abrupt change at measure 135 where there is a return of thematic material that references the lightning strike from the first movement for both instruments. Measure 139 is an example of an instance where each instrument has nearly identically notated parts. In this measure the graphic notation instructs both performers to lower and raise the inflection of the tone, creating a pulsation sound. The thematic material of the saxophone and derabucca are similar until the end of this work.

The greatest challenge in performing this work is realizing the ideas implied in the notation as well as creating varying tone distinction. Once the concepts of the notation and techniques are understood, the derabucca performer has the flexibility to create music beyond the notes on the page, bringing the music to life through improvisation, adding subdivisions, and other subtleties. The notational system El-Dabh created for The Miraculous Tale is unique to this work in that it is largely designed for hand-to-hand execution. This writing style allows for a relaxed, flowing line that will give clarity to the expressive aspects of the derabucca part. 


\section{CHAPTER 4: SWEET AND PRICKLY PEAR}

Composed for violin and derabucca, Halim El-Dabh's Sweet and Prickly Pear draws from his childhood memories of waking up in the morning and having a strong desire for the prickly pear fruit. Often a local push cart vendor would come by the house shouting "teen shoky," which translates to "thorny figs" or what is known as "prickly pear." El-Dabh would anxiously await as the vendor skillfully prepared the fruit for him to enjoy. In this work, El-Dabh expresses the feeling of excitement, delight, and satisfaction that would come from the experience of eating this fruit. ${ }^{31}$ The premiere performance was recorded in the Carl F. W. Ludwig Recital Hall of Kent State University in Kent, Ohio with Jameson Cooper performing the violin and El-Dabh, the derabucca. ${ }^{32}$

\section{Performance Suggestion and Interpretation}

\section{Notation and Sounds}

Similar to Sonic No. 7 and No. 10 and The Miraculous Tale, El-Dabh's writing for the derabucca in Sweet and Prickly Pear is intended to explore the varying sonic possibilities of the instrument. In this work, the notation is designed so that both the violin and derabucca use a traditional 5-line staff to designate sound distinction. Unlike the violin, the lines and spaces of the staff are not intended to indicate specific pitches for the derabucca but relative relationship to each of the primary tones as described on a continuum of sound from low, medium, and high (Figure 4.1). This is El-Dabh's most descriptive method of outlining the fundamental sounds of the derabucca.

\footnotetext{
${ }^{31}$ Halim El-Dabh, Sweet and Prickly Pear (Kent, OH: Halim El-Dabh Music, LLC, 2010), liner notes.

${ }^{32}$ Denise A. Seachrist, The Musical World of Halim El-Dabh, (Kent, Ohio: Kent State University Press, 2003), 270.
} 
Figure 4.1. Sweet and Prickly Pear: Primary Sounds (m. 1)

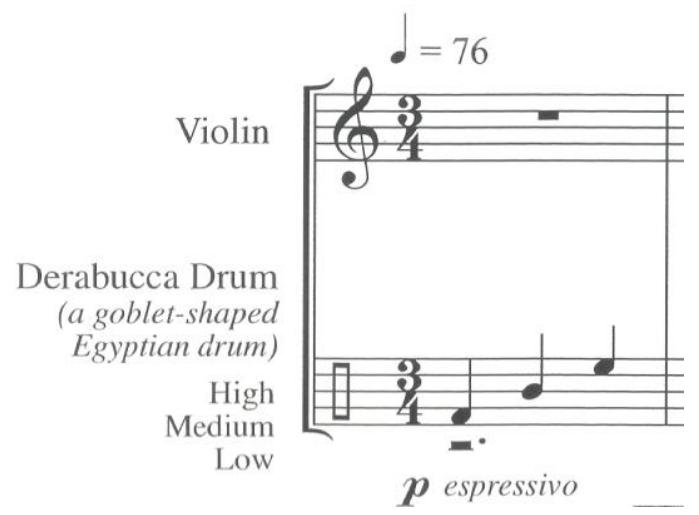

I approach the three sounds of Sweet and Prickly Pear in the same manner as outlined in The Miraculous Tale, using the concept of dum, ma, and tak. El-Dabh's facets of performance from Sonic No. 7 and No. 10 are not individually used for each note in Sweet and Prickly Pear, but are inherent to the sounds described. The stems up (right-hand) and stems down (left-hand) serve as a loose guide to hand and fingering usage in Sweet and Prickly Pear. While this flexibility allows the performer to decide the best method of executing figures throughout this piece, it is important to remember that creating contrasting sound distinction is the most significant aspect of this work. ${ }^{33}$

\section{Techniques}

Beyond the primary sounds described above, there are several additional techniques used to enhance the musical expression of the derabucca throughout this piece. The first technique used in Sweet and Prickly Pear is the pitch bend, executed by retaining the finger on the drumhead and applying pressure. This procedure will raise the sound of the note on beat three

\footnotetext{
${ }^{33}$ El-Dabh, Halim. Interviewed by the author. Kent, Ohio, March 1, 2014.
} 
(Figure 4.2). This is the same technique used in The Miraculous Tale and is designed to expand the sonic capabilities of the derabucca (See Figure 3.5).

Figure 4.2. Pitch Bend Example 1 (m. 2)

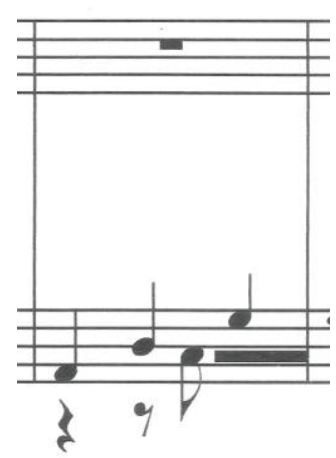

El-Dabh enhances the finger technique with the incorporation of added independent finger action in the right hand. While a left-hand finger is applying pressure, the right hand is executing sixteenth notes in an alternating finger motion with the second and third fingers. I use the momentum of the alternating fingers to bring out the note on beat three performed by the right-hand ring finger. This technique is used consistently throughout the first two pages of the work (Figure 4.3) and is a similar to the technique used in Sonic No. 7 and No. 10 (See Figure 2.29).

Figure 4.3. Pitch Bend Example 2 (m. 12)

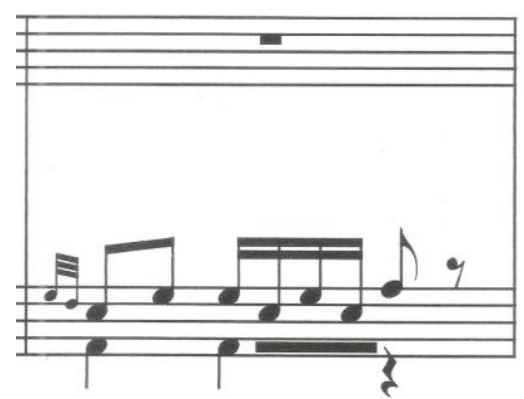


Grace notes are another technique El-Dabh uses in Sweet and Prickly Pear, and similarly to The Miraculous Tale, these embellishments add weight and length to the note (Figure 4.4). I found it best to execute the grace note figure with fingers four and three, leading to finger two. Finger four executes the offbeat of beat one before fingers three and two perform the sixteenth notes of beat two. Although the grace notes are executed in the same hand, this concept is similar to a drag, a common two-hand technique used on the snare drum. Figure 4.5 demonstrates another notated form of grace notes found in this work. I approach these in a similar fashion to a flam on the snare drum.

Figure 4.4. Grace Note Example 1 (m. 3)

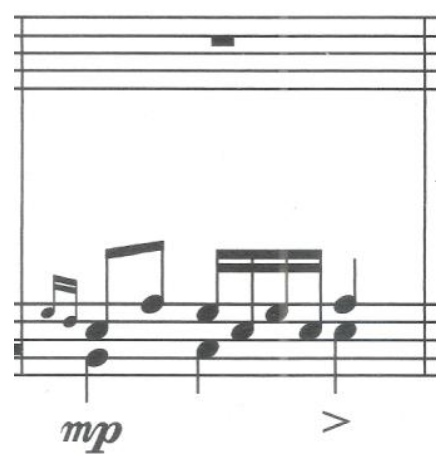

Figure 4.5. Grace Note Example 2 (m. 39)

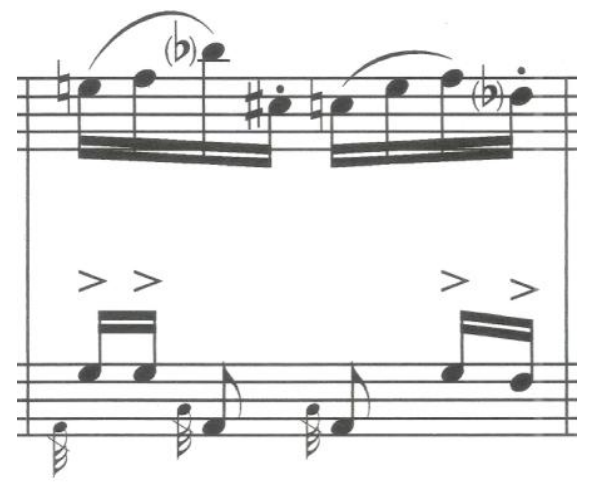


One-handed rolls are another technique El-Dabh uses in this work. This technique is also found in The Miraculous Tale (See Figure 3.12) as well as in Sonic No. 7 and No. 10 (See Figure 2.34). In order to perform this effect and match the volume of the violin in Sweet and Prickly Pear, I found it best to use the thumb and fifth finger of the right hand when executing the roll. The rotating wrist motion used in this technique allows for a strong, consistent sustain (Figure 4.6).

Figure 4.6. Roll Example 1 (m. 10)

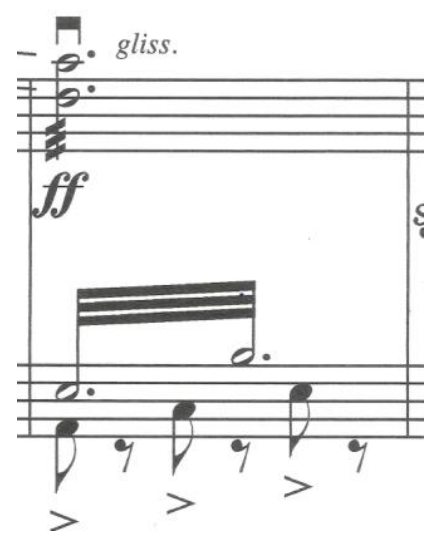

When executing Figure 4.7 the one-handed roll is expanded by incorporating the base of the thumb and adding a circular motion to the hand, enhancing the dramatic rumbling affect depicted by the graphic notation. Moving the left hand around the drumhead as the right performs the sextuplets adds to the sound created. 
Figure 4.7. Roll Example 2 (m. 54 and 55)



\section{Interaction between instruments}

Similarly to The Miraculous Tale, El-Dabh's writing in Sweet and Prickly Pear includes the use of intricate rhythmic ideas between both the violin and derabucca as well as solo opportunities. Throughout the work, both instrumentalists should perform their respective parts in a crisp, articulate, and sharp manner, depicting the prickliness of the pear. Flattening the finger will help with articulation, depth and clarity of sound in the execution of the derabucca part. The finger motion of the derabucca should be executed in a mechanical, even, and structured nature, all the while allowing for shape and contour to the musical passages.

The work begins with a derabucca solo as thematic ideas are introduced. Measures 6 and 7 utilize interlocking sixteenth notes between both the violin and derabucca, creating a dialogue between the instruments. Both the violin and derabucca should perform the rhythms in a strong and deliberate fashion. Maintaining a strict and rigid tempo will solidify the alternating sixteenth notes in both parts of the work.

In measure 10 the derabucca imitates the long sustain of the violin with the use of a onehanded roll. I found it best to execute the roll in the right hand of the derabucca with the first and 
fifth fingers of the right hand. Practicing this technique will ensure that the roll is smooth, even, and independent of the left-hand material. Interlocking thematic ideas continue throughout the second page of the work as another derabucca solo leads into the Lazma section.

When translated, Lazma means "you must." As an obligatory part of the work, the Lazma section is between distinct sections of the composition. ${ }^{34}$ The thematic material of both the violin and the derabucca change starting at the Lazma, where the derabucca establishes a rhythmic groove against the constant sixteenth notes of the violin. Adding to the intensity of the rhythmic figures, the accents can be brought out with a whipping motion of the hand and fingers. The interwoven $32^{\text {nd }}$ notes between the violin and derabucca, throughout the fourth page, need to be exchanged in a seamless fashion.

The Lazma section ends at measure 55 with the derabucca imitating the sextuplets of the violin part in measure 53. It is important that the derabucca performer execute the sextuplets with the same amount of energy and clarity as the violin. Flattening the finger and using more pad instead of finger tips will aid precision and energy required for these figures, giving clarity and body to the sextuplets in the right hand while the left hand rumbles, as discussed in Figure 4.7.

Following the Lazma at measure 56, short rhythmic flourishes of the derabucca contrast the soft, sustaining line of the violin. The flourishes in the derabucca should be crisp and precise, giving a sense of forward motion. These figures should move to the offbeat, filling in the subdivision of the quarter notes of the violin. An imitative passage between the violin and derabucca returns at measure 66 . The response of the derabucca should be executed in a manner

\footnotetext{
${ }^{34}$ Halim El-Dabh, Sweet and Prickly Pear (Kent, OH: Halim El-Dabh Music, LLC, 2010), liner notes.
} 
that the momentum created in the violin part is transferred to the derabucca. Matching the dynamic level and using more of the fingers will assist in emulating the volume of the violin.

Throughout measures $81-90$, new thematic ideas are notated utilizing $32^{\text {nd }}$ notes between both the violin and derabucca, requiring precise execution of the rhythms. The Lazma returns and continues until measure 123. From this point until the end of the piece, El-Dabh blends and expands thematic ideas from previous sections of the piece.

It is important to remember that the notation for Sweet and Prickly Pear is a description of what is to take place. Ultimately, once the notation and musical ideas are conceptualized, the technical decisions of how to achieve these sounds are flexible and left to the discretion of the performer. It is important for the performer not to become distracted by the detail of the notation but rather to focus on creating music. Performing with clear rhythmic and melodic precision will enhance the interwoven dialogue between the violin and derabucca.

Similarly to Sonic No. 7 and No. 10 and The Miraculous Tale, the greatest challenge in performing this work is realizing the notation as well as creating varying tone distinction. A unique aspect to Sweet and Prickly Pear is that rhythmic embellishment is reliant on independent finger action rather than hand-to-hand motion when compared to The Miraculous Tale. Once the concepts of the notation and techniques are understood for all the aforementioned works, the derabucca performer then has the flexibility to create music beyond the notes on the page, bringing the music to life. The notational style El-Dabh developed for Sweet and Prickly Pear is unique to this work and useful to the performer in that it clearly demonstrates the concept of the melodic contour El-Dabh aims to portray on the derabucca. El-Dabh created this system because 
he felt this notational design optimized the musical expression he aimed to capture in this piece. $^{35}$

\footnotetext{
${ }^{35}$ Halim El-Dabh, interview by the author, personal interview, Kent, Ohio, February 9, 2013.
} 


\section{CHAPTER 5: FURTHER APPLICATION OF TECHNIQUES}

This chapter will discuss how El-Dabh's writing for the derabucca has evolved and how the performance techniques can be transferred to other related percussion instruments.

Conclusions will be supported by examples demonstrating common techniques employed in the performance of these three selections. The three works examined in this document demonstrate a shift in El-Dabh's compositional style from a prescriptive approach used in Sonic No. 7 and No. 10, to a descriptive approach used in The Miraculous Tale, and Sweet and Prickly Pear. The precise symbol designations of the performance facets (placement, position, resonance, fingering, and touch) used in Sonic No. 7 and No. 10 are not notated in the other two works, allowing the technical aspect of sound production to be determined at the performer's discretion.

Published in 1965, Sonic No. 7 and No. 10 is considered the first known published work for solo derabucca in the United States. This piece emerged during the time when there were significant developments happening in musical notation and the training of percussionists. Throughout the 1950's and 1960's composers such as John Cage, Karlheinz Stockhausen, and Morton Feldman were creating new forms of notation that began to push the boundaries and challenge the idea of a standardized "musical score." Composers utilized dots, lines, grids and other graphic images and shapes to express music and its interpretation. ${ }^{36}$ El-Dabh's Sonic No. 7 and No. 10 is an example on the notational development timeline when notation was being reexamined, challenged, and questioned by composers whose works did not fit within the traditional notational boundaries.

\footnotetext{
${ }^{36}$ Kurt Stone, Music Notation in the Twentieth Century, (New York: W.W. Norton \& Company, 1980), xiii-xix.
} 
Sonic No. 7 and No. 10 was published during the infancy of college and university percussion instruction. Paul Price at the University of Illinois is given credit for establishing the first course of instruction for percussion ensemble in 1950, marking the beginning of collegelevel percussion education. ${ }^{37}$ As other schools followed suit, it led to more trained percussionists and eventually a greater demand for repertoire for percussion. Because of the limited universitylevel instruction available at the time and relatively low number of Western-trained percussionists interested in world percussion instruments, El-Dabh assumed the performer had little knowledge about the performance practice of the derabucca. For this reason he provides highly detailed instruction in Sonic No. 7 and No. 10 to express his intentions.

While the detailed notation of Sonic No. 7 and No. 10 is very informative, creative, and highly developed, it is important for the performer not to be overwhelmed by the minutiae of the score. Once the concepts are understood I found it best to take a step back and formulate bigger ideas from the detail provided. Ultimately the details of the notation aim to hone in on the intended sound. Grouping many of the intricate details and organizing them into a larger idea will help develop consistency in performance as well as improve the process of reading and conceptualizing the notation for this work. Over time, El-Dabh has naturally made this type of adjustment in his writing style for the derabucca. Percussionist Steven Schick offers an interesting perspective on notation stating, "In light of the ambiguities of percussive material, it seems that the more painstaking the notation, the less likely it can be reproduced with accuracy over time. ${ }^{138}$ Fifty years after composing Sonic No. 7 and No. 10, El-Dabh's writing style for the derabucca in Sweet and Prickly Pear and The Miraculous Tale reflects this idea as he utilizes a

\footnotetext{
${ }^{37}$ Gordon B. Peters, The Drummer: Man, (Wilmette, Illinois: Kemper-Peters Publications, 1975), 211.

${ }^{38}$ Steven Schick, The Percussionist's Art, (Rochester, New York: University of Rochester Press, 2006), 59.
} 
more descriptive notational approach. In The Miraculous Tale and Sweet and Prickly Pear, the notation is much less prescriptive and "spelled out" than in Sonic No. 7 and No. 10.

\section{Application of Techniques}

Studying music rooted in other cultures offers insight into diverse performance techniques, styles, and repertoire, expanding a performer's level of musical expression. Through the process of imitation, adaptation, and by combining techniques from a variety of instruments, a performer can shape and expand his or her musical ideas, creating a unique musical voice. A broadened skill set enhances a performer's control, tone production, and technical facility on a multitude of percussion instruments.

Glen Velez, considered the father of modern frame drumming, epitomizes the concept of adapting and transferring techniques to other instruments. Velez has studied various frame drumming styles and instruments from around the world and through this process, has created a unified playing vocabulary that can be used on a variety of instruments including the South Indian kanjira, Nubian tar, Moroccan bendir, Arab riqq, and Irish bodhran. In developing a global approach through the blending of various techniques and cultural styles, he has formed his own unique and influential musical voice. El-Dabh's works for derabucca serve as a viable model for furthering a performer's technique and musicianship by emulating Velez's example to achieve a high level of musicianship across many hand drums.

A work that demonstrates the concept of transferring performance practices to other instruments is Robert Damm's Udu Dances. Originally written for the udu drum, Damm discusses in the preface that this work can be performed on other instruments such as a conga, 
derabucca, or djembe. These optional instruments work well, because similarly to the udu drum, each has three fundamental tones that range from low, medium, and high. The congas's and djembe's three fundamental sounds are taught as bass, tone, and slap, fitting the low, medium, and high tone spectrum. These sounds also equate to $d u m, m a$, and tak on the derabucca. The technique and hand positioning is comparable between these instruments and all have the potential for expanded sonic possibilities through ornamentation such as finger rolls, pitch bends, mutes, slaps, and development of textural elements.

The concepts presented in Sonic No. 7 and No. 10, The Miraculous Tale, and Sweet and Prickly Pear can easily be applied and transferred to improve a player's ability and musicianship not only on the derabucca but on other ethnic instruments such as the previously mentioned tar, bendir, udu drum, riqq, bodhran, in addition, the Nigerian udu drum. These instruments work well for substitution due to similar performance posture, hand placement, and the fact that technique is largely finger oriented like the derabucca. While these pieces could be adapted to other instruments with slight adjustments made to facilitate idiomatic technique of the instrument, below are examples of specific figures within the works studied in this document that can easily be transferred to other instruments and executed in a similar manner.

The sixteenth-note rhythmic figure on the first three beats of measure 17 of Sonic No. 7 could be applied to a bendir, tar, or other types of frame drums. Using the momentum of fingers two and three for the sixteenth notes and ending with a flick of the wrist utilizing the fourth finger on the rim of the drum will work well for execution as well as pitch distinction on any of the aforementioned instruments (See Figure 2.29). 
Another example of an adaptable technique is from measure 25 of Sonic No. 7. Scored in the left hand of this work, the contrasting sounds of the curvature of the hand will fit well when performed with the dominant hand on a tar, bodhran, or other large frame drum performed lap style (See Figure 2.23). Lap style is when the player sits and holds the instrument on the nondominant knee with the non-dominant hand on top. In this position, the head of the drum is away from the performer. This technique is necessary when the frame drum is too large to be controlled by the hands (Figure 5.1).

Figure 5.1. Lap Style Tar

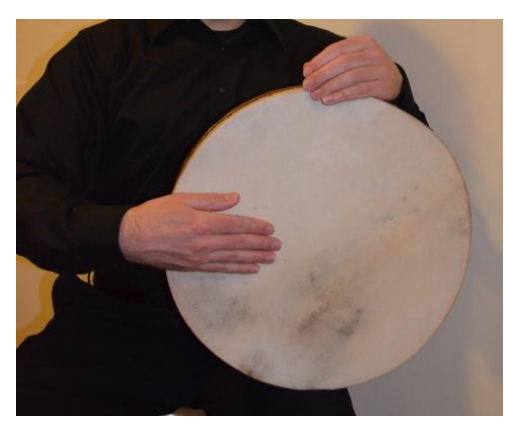

The finger roll found in measure 39 is another example of a transferable technique to multiple instruments. By utilizing various finger combinations in addition to changing placement, this technique would be effective for any style of frame drum as well as an udu drum. Roll speed can be altered, adding another expressive aspect to this procedure. Keeping the hands relaxed will aid in a seamless transition between finger combinations. When the roll utilizes fingers one and five on a frame drum, or udu drum more rotation of the wrist is needed when compared to using fingers two and three. Measure 39 of Sonic No.7 is a contextual example of the finger roll and placement change (See Figure 2.34). 
The pitch bend notated in measure two of Sweet and Prickly Pear is an effective technique on any frame drum in lap style position. Applying pressure to the head of the drum with a finger or multiple fingers serves to expand the sonic spectrum beyond the primary sounds of low, medium, and high. In the example below, El-Dabh uses a solid line following beat two, instructing the performer to apply pressure with the finger, allowing the tone on beat three to sound higher (See Figure 4.2).

Grace notes are another example of ornamentation that can be adapted to other instruments. This musical gesture works well on a variety of instruments such as an udu drum, tar, bohdran, and bendir and can be executed a number of ways. Using the finger tips, pads, and nails all offer a different sound and texture. Finger combinations as well as placement are varying aspects of this technique and can be adapted at the discretion of the performer. Measure nine of The Miraculous Tale represents a notated example of this technique (See Figure 3.9).

While the above techniques are adaptable to other non-western instruments, the underlying concepts are also present and easily transferred to concert percussion. Elliot Carter's Eight Pieces for Eight Timpani is a comparable example of using varying techniques to explore the sonic qualities of an instrument similar to El-Dabh's exploration of sound in his compositions. In his work, Carter manipulates sound through altering the playing spot, using harmonics, dampening and muting, and requiring different implements to create varied sounds on a single-headed drum. The concept of these techniques and the manipulation of sound is similar to El-Dabh's facets of performance. In Carter's work, similar to El-Dabh's works for derabucca, it is important that the performer achieve clarity of sound. In both cases clear distinction will produce contrast, and therefore greater effectiveness of the sounds achieved 
through these techniques. Carter's Eight Pieces for Eight Timpani is an excellent example of how El-Dabh's concepts are transferable across Western and non-Western percussion instruments.

\section{Conclusion}

It is my hope that this study will aid a performer's preparation of Halim El-Dabh's works for derabucca and will offer greater insight from the performer's perspective concerning advanced musical techniques for the instrument. Because these works are unique in their notational styles, a performer can benefit from the specific information gathered in this document to aid in the interpretation and execution of these works. Additionally, as an instrument primarily based in oral tradition, El-Dabh's repertoire not only serves as a notated source for advanced derabucca techniques but also as a platform for increasing musical skills and techniques for other hand percussion instruments.

Through the process of learning and performing Sonic No. 7 and No. 10, Sweet and Prickly Pear, and The Miraculous Tale, the advanced techniques utilized have shaped and developed my sound as a performer. These techniques serve as a platform for expanding my musical vocabulary, style, and nuance in a variety of musical situations and have a practical application to other instruments. Through mastery of traditional and innovative techniques, I have expanded my technical facility allowing for increased artistic expression on other similar hand and frame drum instruments. Studying this repertoire also expanded my approach and ability to decipher new and unique musical notation systems, a common demand of the 
contemporary percussionist. These techniques have improved my skills and will be beneficial throughout my future teaching and performance. ${ }^{39}$

It is my further hope that this study will inspire percussionists unfamiliar with El-Dabh's music to perform his works and adapt these techniques in the performance of other repertoires, expanding the musical outlet for the instrument. As this instrument continues to gain recognition, I anticipate more percussionists will become aware of Halim El-Dabh's writing for the derabucca. Additional research will be needed concerning the performance practice of similar goblet-shaped drums. While notation is not standardized for the derabucca and similar drums, there are compelling reasons for both performance-related and notation-related aspects to be unified and approached with more consistency. Further research would be beneficial concerning the melodic as well as rhythmic functions of the derabucca within both traditional and contemporary musical settings. The sonic possibilities for the derabucca are indeed endless and El-Dabh's repertoire serves as a source to shape one's musical voice on the instrument.

\footnotetext{
${ }^{39}$ I have video demonstrations available and can be reached at ryanjfrost@yahoo.com.
} 


\section{BIBLIOGRAPHY}

Aspiotes, Gust. Learn to Play the Dumbeg. Hollywood, Calif: TRY Publications, 1977.

Beach, Michael, Gustavia Miller, and Krystal Kroker. Basic Middle Eastern Drums \& Rhythms. Portland, Ore: Brothers of the Baladi, 1992.

Beck, John H. Encyclopedia of Percussion. 2nd ed. New York: Routledge, 2007.

Blades, James. Percussion Instruments and Their History. London: The Bold Strummer, Ltd., 2005.

Cook, Gary D. Teaching Percussion. 3rd ed. Belmont, CA: Thomson Schirmer, 2006.

Crafton, Randy. “Omar Faruk Tekbilek The Turkish Tradition.” Percussive Notes 38 (October 1999): 38-40.

Danziger, Raquy. "Introduction to the Dumbek." Percussive Notes 43 (October 2005): 44-47.

Danziger, Raquy. Dumbek Fever: Dumbek Instructional Kit. Brooklyn, N.Y.: Jordan Press, 2006.

DiSanza, Anthony. Concerto for darabukka and percussion quartet. Everett, PA: HoneyRock, 2007.

Donald, Mary Ellen. Doumbec Delight: A Thirty Lesson Course in Middle Eastern Drumming with Basic Music Theory. San Francisco: Mary Ellen Books, 1979.

El-Dabh, Halim. Interview by author. Phone interview. Kent, OH, April 4, 2015. . Interview by author. Phone interview. Kent, OH, May 11, 2014.

. Interview by author. Phone interview. Kent, OH, March 1, 2014.

. Interview by author. Phone interview. Kent, OH, December 10, 2013.

. Interview by author. Phone interview. Kent, OH, December 7, 2013.

. Interview by author. Personal interview. Kent, OH, February 9, 2013.

. The Derabucca; Hand Techniques in the Art of Drumming. New York: C.F. Peters Corp, 1965.

. The miraculous tale: for alto saxophone and derabucca. Kent, OH: Halim El-Dabh Music, 2010. 
Sonic, no. 7 and no. 10: derabucca or multiple drums. New York: C.F. Peters Corp, 1965.

. Sweet and prickly pear: for violin \& derabucca : 2nd version--2009. Kent, Ohio: Halim El-Dabh Music, 2010.

. Tabla-dance; piano and percussion ensemble (3 to 5, 9 or more players). New York: C.F. Peters Corp, 1965.

. Tabla-tahmeel, no. 1: percussion ensemble (3 or 6, 7, 9, 12, 14 players). New York: C.F. Peters Corp, 1965.

. Symphony for one thousand drums. Kent, Ohio: Halim El-Dabh Music, 2010.

Gocmez, Behnan. Darbuka Method: Advanced Darbuka Technique. Pacific, MO: Mel Bay, 2001.

. Darbuka technique: rhythmic solfege, theory, exercises, solos. Groningen:

Coppercussion, 1900.

Guida, Carmine T. Begintermediate Doumbek Workshop. [S.1.]: Carmine T. Guida, Inc, 2007.

Houshan, Issam. Introduction to Middle Eastern Rhythms for Percussionists and Bellydancers. Universal City, CA: Vivendi Entertainment, 2009.

James, Gerry, Robin Adnan Anders, Ben James, Cecilia Mastrorilli, Javier Cafaro, Kas Kasprowicz, Michael Miner, and Eric Bergman. Voices of the Doumbek Utilizing the Doumbek/Arabic Tabla and Dourbakee Drums. Brattleboro, VT: Interworld Music, 1995.

Kaspar, Souhail. Souhail Kaspar's Egyptian tablah (doumbek) for intermediate \& advanced drummers. Encino, CA: SK Near East Music, 2009.

Kessler, Jonathan. The Doumbek Video. Fort Bragg, CA: Lark in the Morning Videos, 2002.

_. "Turkish and Armenian Rhythms for American Drummers." Percussive Notes 33 (June 1995): 39-44.

Kuckhermann, David. World Percussion 1: Riq and Darbuka. MusiCircus. (DVD). . World Percussion 1: Framedrums. 2006. MusiCirucus. (DVD) . Advanced Frame Drums 1. 2009. One World Percussion. (DVD) . Advanced Frame Drums II. 2009. One World Percussion. (DVD) . "Persian Techniques on Hand Drums." Percussive Notes 70 (October 2007): 70-71. 
Leigh, Marla and Ken Shorley. Time Zone: Duets for Darabuka and Frame Drum. 2004 (DVD).

Mel Bay Publications. “The Magnificent Darbuka Rhythms: A beginner's guide to learning how to play popular Middle Eastern rhythms.”

Mohamed, Jamal. “The Arabic Doumbek.” Percussive Notes 48 (September 2012): 20-23.

Muallem, Yinon. “Arabic Percussion.” DVD.

Nagi, Karim, Mher Panossian, and Lauren-Michelle Boldt. Rhythms of the Arab World. Essential Technique and Rhythms . Vol. 1. Glendale, CA: Hollywood Music Center, 2008.

Naoum, Amir. Doumbek Technique \& Rhythms for Arabic Percussion, Bellydance, Drum Circles. New York: StratoStream/WorldDance, 2006.

Nicholson, Jason Eugene. "Selected Works for Solo Frame Drums by B. Michael Williams." D.M.A. diss., University of North Texas, 2009.

Parks, Robert Eugene, Jr. "A Survey of Frame Drumming in the United States.” D.M.A. diss., University of Kentucky, 2011.

Peters, Gordon B. The Drummer: Man, a Treatise on Percussion. Rev. ed. Wilmette, Ill.: Kemper-Peters, 1975.

Ragheb, Nicholas Joseph. From Darbuka to Dümbelek The Turkish Goblet-Shaped Drum and the Construction of Difference. Austin, Tex: University of Texas, 2012.

Roach, Todd, Fred Stubbs, and Ben James. The quick guide to playing doumbek featuring Todd Roach. New York: Carl Fischer, 2004.

Robinson, N. Scott, Larry Barbee, Vince Giardina, Glen Fittin, and Stephen Wright. Hand Drumming Exercises for Unifying Technique Featuring the Ubang. Hagerstown, Md: Wright Hand Drum Co, 1996.

Robinson, N. Scott. "Okay Temiz: Drummer of Many Worlds." Percussive Notes 28 (August 2003): 28-35.

Salloum, Trevor K., and Michel Merhej Baklouk. The Art of Arabic Drumming. Pacific, MO: Mel Bay Publications, 2007.

Schick, Steven. The Percussionist's Art: Same Bed, Different Dreams. Rochester, NY: University of Rochester Press, 2006.

Seachrist, Denise A. The Musical World of Halim El-Dabh. Kent, OH: The Kent State University Press, 2003. 
Seeger, Charles. Prescriptive and Descriptive Music Writing. Musical Quarterly. xliv, no. 2: 184195. 1958.

Sheronick, Yousif. Advanced Frame Drum Techniques, 2009, DVD.

Sheronick, Yousif. "Juilliard Darbuka Solo” (video). September 16, 2009. Accessed December 14, 2012. http://www.youtube.com/watch?v=zENRNvFs-rk.

Stone, Kurt. Music Notation in the Twentieth Century: A Practical Guidebook. New York: W.W. Norton and Company, 1980.

Turku (Musical group). Columbia, S.C.: [Hittite Sun Records], 2004.

Uncle Mafufo, and Hanya le Flash. Uncle Mafufo's Basic Rhythms for Arabic Drum. Plus Live Concert Performance Volume 1. Capitola, Ca: Fojaco Productions, 2003.

Williams, B. Michael. “Dror Sinai Doumbek.” Percussive Notes 26 (October 2004): 26.

Wilson, Susan. Darbuka rhythms for Oriental dance practice Vol. 1 \& Vol. 2. Tucson, Ariz: Llamavision, 1987. 